Article

\title{
Regional Models for High-Resolution Retrieval of Chlorophyll $a$ and TSM Concentrations in the Gorky Reservoir by Sentinel-2 Imagery
}

\author{
Alexander A. Molkov ${ }^{1,2, *(\mathbb{D})}$, Sergei V. Fedorov ${ }^{3}$, Vadim V. Pelevin ${ }^{4}(\mathbb{D}$ and \\ Elena N. Korchemkina ${ }^{3}$ \\ 1 Institute of Applied Physics of the Russian Academy of Sciences, 46 Uljanova st., \\ 603950 Nizhny Novgorod, Russia \\ 2 Division of Ship Hydrodynamics and Ecological Safety of Ship Navigation, Volga State University of Water \\ Transport, 5 Nesterova st., 603950 Nizhny Novgorod, Russia \\ 3 Marine Hydrophysical Institute of the Russian Academy of Sciences, 2 Kapitanskaya St., 299011 Sevastopol, \\ Russia; s.fedorov.mhi@gmail.com (S.V.F.); lisenik@mail.ru (E.N.K.) \\ 4 P.P. Shirshov Institute of Oceanology, 36 Nakhimovsky Prospekt, 117997 Moscow, Russia; pelevin@ocean.ru \\ * Correspondence: a.molkov@inbox.ru; Tel.: +7-831-416-4859
}

Received: 23 April 2019; Accepted: 20 May 2019; Published: 22 May 2019

\begin{abstract}
The possibilities of chlorophyll $a(\mathrm{Chl} a)$ and total suspended matter (TSM) retrieval using Sentinel-2/MSI imagery and in situ measurements in the Gorky Reservoir are investigated. This water body is an inland freshwater ecosystem within the territory of the Russian Federation. During the algal bloom period, the optical properties of water are extremely heterogeneous and vary on scales of tens of meters. Additionally, they vary in time under the influence of currents and wind forcing. In this case, the usage of the traditional station-based sampling to describe the state of the reservoir may be uninformative and not rational. Therefore, we proposed an original approach based on simultaneous in situ measurements of the remote sensing reflectance by a single radiometer and the concentration of water constituents by an ultraviolet fluorescence LiDAR from a high-speed gliding motorboat. This approach provided fast data collection including 4087 synchronized LiDAR and radiometric measurements with high spatial resolutions of $8 \mathrm{~m}$ for two hours. A part of the dataset was coincided with Sentinel-2 overpass and used for the development of regional algorithms for the retrieval of Chl $a$ and TSM concentrations. For inland waters of the Russian Federation, such research was performed for the first time. The proposed algorithms can be used for regular environmental monitoring of the Gorky Reservoir using ship measurements or Sentinel-2 images. Additionally, they can be adapted for neighboring reservoirs, for example, for other seven reservoirs on the Volga River. Moreover, the proposed ship measurement approach can be useful in the practice of limnological monitoring of inland freshwater ecosystems with high spatiotemporal variability of the optical properties.
\end{abstract}

Keywords: Sentinel-2; high-resolution imagery; ACOLITE; LIF LiDAR; UFL-9; chlorophyll $a$; TSM; Gorky Reservoir; bio-optical properties of water; inland water; lakes

\section{Introduction}

The largest cities, industrial centers, and agricultural lands are often located on the banks of inland waters. Their overall prolonged impact on the aquatic environment and specific hydrological characteristics of inland waters lead to significant declining of water quality [1,2]. Self-purification mechanisms existing in the seas and oceans are weak [3] in inland waters. Due to the importance of freshwater bodies for human activities, much attention is paid to the monitoring of their quality. 
For these reasons, regional bio-optical algorithms for retrieval of water quality parameters from satellite images [4-6] are developed for many lakes and reservoirs all over the world. In the Russian Federation, unlike Europe, Asia or America, such algorithms were developed for significantly fewer water bodies: the Ivankovo [7], the Krasnoyarsk [8], and the Gorky [9] Reservoirs, and the Lakes Baikal [10,11] and Ladoga [12]. These studies were limited by retrieval of $\mathrm{Chl} a$ concentration by regression to Level 2 (L2) satellite data. The radiometric measurements and atmospheric correction were not performed. Meanwhile, the amount of the Russian inland waters which are important for ensuring human activities and protection of unique flora and fauna is significant. Among them there a great deal of highly productive reservoirs with different sizes from tens to hundreds of kilometers. The presence of regular channel currents and variable wind forcing leads to significant spatial-temporal variability of their water optical properties on scales of tens of meters and some hours. These factors limit the usage of the MODIS and Landsat-7,8 data due to insufficient resolution and low revisit interval (16 days), respectively.

MSI (MultiSpectral Instrument) optical sensors installed on Sentinel-2 satellites are a promising tool for studying of inland freshwater ecosystems [13]. Despite the fact that the main purpose of Sentinel-2 is global land monitoring, there are some studies demonstrating the possibility of its usage for assessment of inland water quality. In particular, in [14] the signal-to-noise ratio of MSI bands relative to water bodies was estimated, the atmospheric correction (AC) in SeaWiFS Data Analysis System (SeaDAS) was carried out, its accuracy according to AERONET-OC was estimated, and vicarious calibration was performed. In [15], different AC methods for MSI images by in situ radiometric measurements in four Amazon lakes were evaluated. Authors showed significant accuracy variations for all spectral bands depending on the water optical properties of studied lakes. Additionally, the water reflectance above $705 \mathrm{~nm}$ is sensitive to the adjacency effect. Similar results were obtained for Lake Starnberg, Germany [16].

The possibility of MSI bands usage for constituent estimation and the development of appropriate bio-optical algorithms were studied in [17-23]. The accuracy of the Chl $a$ retrieval algorithm for eutrophic waters developed for MODIS, MERIS, and other ocean color sensors was evaluated using MSI data by Grendaite [17]. In [18], calibration and validation of well-proven algorithms [24,25] were performed by in situ measurements in the Barra Bonita Reservoir, Brazil. The suitability of the commonly used green to red band ratio was tested for estimation of the colored dissolved organic matter (CDOM), dissolved organic carbon (DOC), and water color in Estonian lakes with different trophic state indices in [19]. Empirical relation with CDOM absorption coefficient was obtained by the usage of the model radiance spectrum [20]. At the same time, Kutser showed that information on Chl $a$ and TSM concentrations in CDOM-rich lakes can be obtained from peaks at 710 and $810 \mathrm{~nm}$ using B5 $(705 \mathrm{~nm})$ and B7 $(783 \mathrm{~nm})$ bands [21]. In [22], the single-band algorithm for TSM concentration retrieval was developed for Lake Poyang, China. In [23], the TSM retrieval algorithm [26] was successfully applied to B4 band and the consistency between Sentinel-2A/2B and Landsat-8 data was shown.

The most part of algorithms for the processing of the MSI data is developed on the basis of in situ measurements for inland waters with smooth heterogeneity of optical properties. The last one strongly differs for the waters of the Gorky Reservoir during the algal bloom period. The spatial patterns of Chl $a$ concentration vary in time so rapidly that satellite image may not correspond to in situ data after a few hours or faster. Another problem is the regular presence of cumulus and cirrocumulus clouds. In this case, some stations for sampling can appear under clouds or its shadow in a satellite image. Therefore, the usage of the traditional station-based measurements may not be rational. On the one hand, it will require a large number of expeditions to obtain statistically valid results. On the other hand, it will require additional significant financial and time costs for laboratory analysis of water samples, which may be useless due to above-mentioned reasons. Thus, another approach of in situ measurements may be required in order to minimize these risks and conservation of the results reliability. One of them is proposed in the present paper. The obtained in situ data were used to investigate practical possibilities 
of Sentinel-2/MSI for inland waters with high spatiotemporal variability of the water optical properties on the example of the Gorky Reservoir.

\section{Materials and Methods}

\subsection{Study Area}

The Volga River is the main waterway of central Russia and the longest European river. Its current ecological state is under the close attention of environmentalists due to shoaling, pollutions and phytoplankton blooms [27-29]. The last factor is the most pronounced in reservoirs of the upper and middle Volga, for example, in the Gorky Reservoir. This reservoir $\left(56.65^{\circ}-58.08^{\circ} \mathrm{N}, 38.83^{\circ}-43.37^{\circ} \mathrm{E}\right)$ has $427 \mathrm{~km}$ long and covers $1590 \mathrm{~km}^{2}$ (Figure 1). Its volume is $8.71 \mathrm{~km}^{3}$. Average and maximum depths are $3.65 \mathrm{~m}$ and $26.6 \mathrm{~m}$ respectively. A shipping channel of the Volga River runs along the reservoir (Figure 1a). The last $100 \mathrm{~km}$ forms a lake (Figure 1b). The lake part is well suited for studying different hydrophysical processes due to the presence of unique features of hydrology, variety of winds and current velocities, intensive phytoplankton bloom [30-35]. Specific parameters that quantitatively characterize the hydrological and bio-optical regimes of the Gorky Reservoir are presented in Table 1.
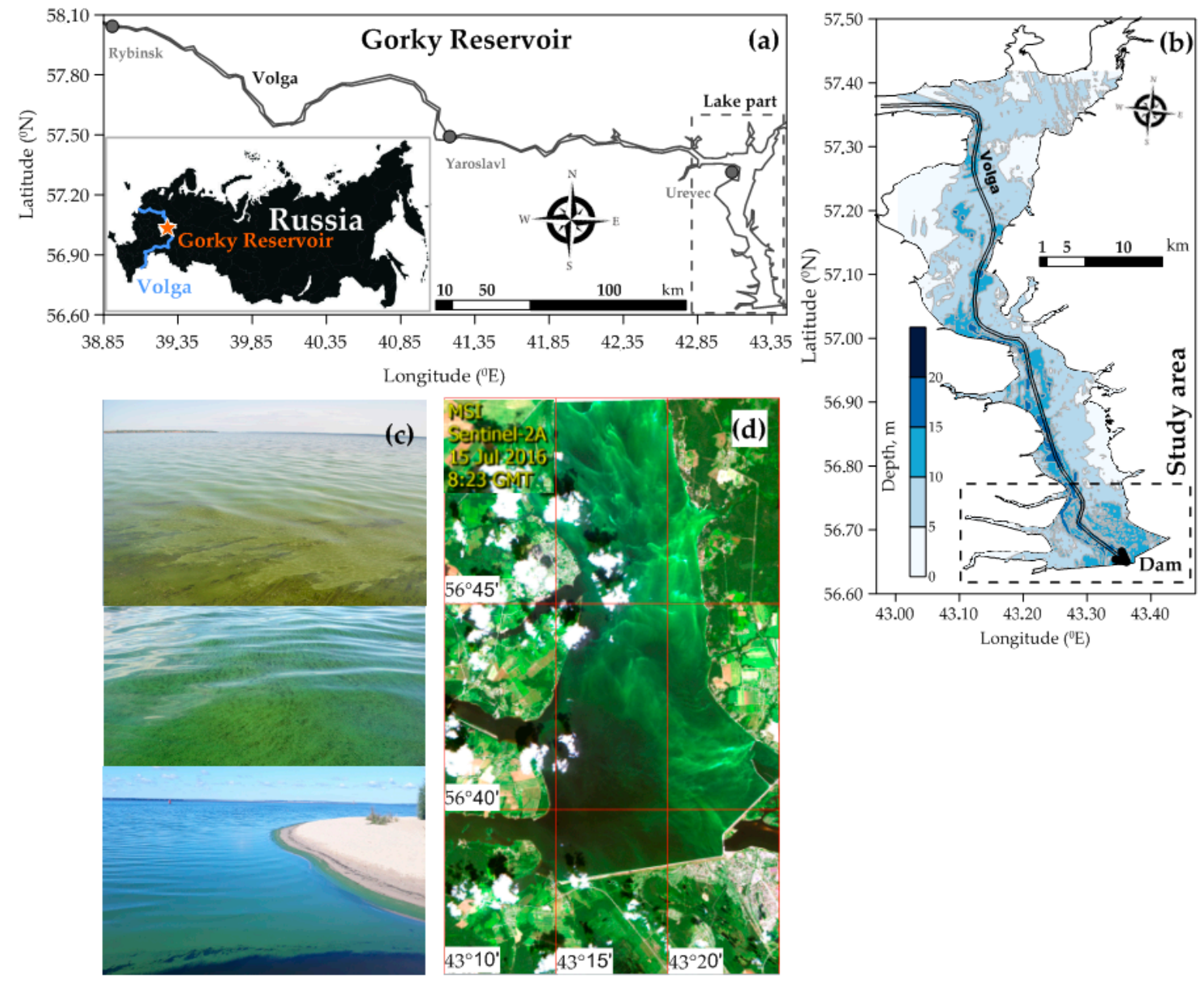

Figure 1. The Gorky Reservoir: (a) basic map; (b) the lake part map; (c) photo of a cyanobacteria bloom; and (d) Sentinel-2A true color image (15 July 2016) of cyanobacteria bloom.

According to $[30,31,34]$, the intensive phytoplankton bloom (Figure 1c) is observed from June through October and basically presented by algae of green, blue-green, cryptophytes, and diatom species. During this period there is quantitative domination of the blue-green algae, represented by Aphanizomenon flos-aquae (L.) Ralfs ex Born. et Flah., Anabaena sp., Anabaena flos-aquae Bréb. ex Born. 
et Flah., Merismopedia tenuissima Lemm., Microcystis aeruginosa (Kütz.) Kütz., Microcystis wessenberdgii (Kom.) Kom. In calm weather, the algal spatial distribution is highly heterogeneous, as demonstrated by the Sentinal-2A image of 15 July 2016 (Figure 1d). There are various structures in this image: sharp fronts with the spatial scale of tens of meters, large-scale areas of quasi-uniform distribution, and vortex structures with increased concentrations of algae. These structures move with average speeds of 3-5 cm/s under the action of channel current [35]. This leads to algal shifting of more than 100-200 $\mathrm{m}$ per $1 \mathrm{~h}$ and more than $2.5-5 \mathrm{~km}$ per day. At windy weather, shifting speed may increase and reach values more than $7 \mathrm{~cm} / \mathrm{s}$. As an example, large-scale algal shifting from the right bank to the left one under west wind proceeded four days is shown by a series of MODIS images in Figure 2. According to archival meteorological data [36], west and northern winds are regular and continual for this region. Generated wind waves have maximum fetch and effect on the vertical mixing of algae. As a result, it leads to a decrease of phytoplankton concentration in the near surface water layer where the satellite signal is formed. These factors limit the applicability of traditional station-based measurements of remote sensing reflectance $\left(R_{r s}\right)$ and water sampling and require another approach for in situ measurements.

Table 1. Hydrological and bio-optical characteristics of the lake part of the Gorky Reservoir according to authors own measurements of 2016-2018 years [34,35] and previous studies [30-33].

\begin{tabular}{cc}
\hline Parameter & Value \\
\hline Maximum depth, $\mathrm{m}$ & 26.6 \\
Average depth, $\mathrm{m}$ & 3.65 \\
Maximum current velocity, $\mathrm{cm} / \mathrm{s}$ & 12.0 \\
Average current velocity, $\mathrm{cm} / \mathrm{s}$ & 3.0 \\
Average wind speed, $\mathrm{m} / \mathrm{s}$ & 1.7 \\
Average wind gust speed, cm/s (for a $10 \mathrm{~min}$ interval) & 3.3 \\
Average wind gust speed, cm/s (for a $1-\mathrm{min}$ interval) & 14.3 \\
Prevailing wind direction & $\mathrm{SW}$ \\
Maximum water temperature, ${ }^{\circ} \mathrm{C}$ & 32 \\
Chlorophyll a concentration, $\mathrm{mg} / \mathrm{m}^{3}$ & $0.5-460$ \\
TOC concentration, $\mathrm{mg} / \mathrm{L}$ & $9-21$ \\
TSM concentration, $\mathrm{mg} / \mathrm{L}$ & $5-20$ \\
Secchi depth, $\mathrm{m}$ & $0.2-3.5$ \\
Photic zone depth, $\mathrm{m}$ & $1.0-4.1$ \\
Trophic state index & eutrophic \\
\hline
\end{tabular}

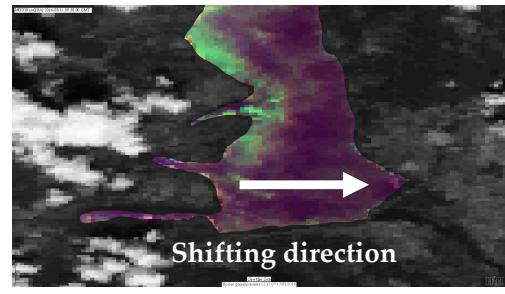

(a)

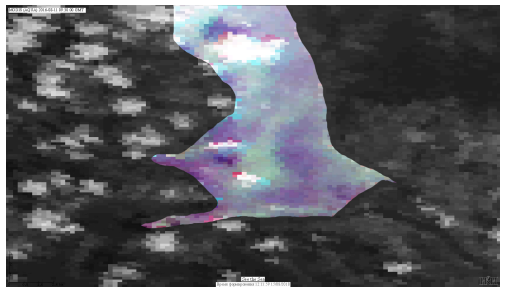

(b)

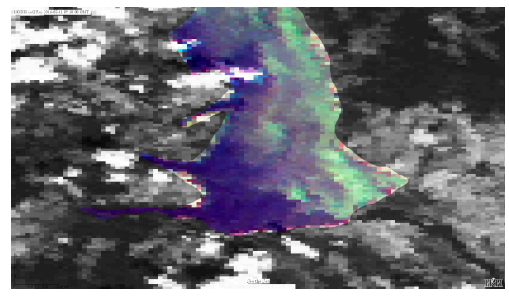

(c)

Figure 2. MODIS images of the Gorky Reservoir illustrating the process of algal bloom shifting from the right riverside to the left one under wind forcing: (a) 29 July 2016, (b) 30 July 2016, and (c) 1 August 2016.

\subsection{Field Measurements}

\subsubsection{Approach Description}

The necessity of a suitable approach for in situ measurements in the Gorky Reservoir was determined by the following reasons:

1) strong heterogeneity of phytoplankton on scales from tens to thousands of meters; 
2) short lifetime of phytoplankton distribution relative to the moment of satellite overpass due to river current and wind forcing; and

3) potential possibility to study small-scale patterns with sizes of tens of meters using Sentinel-2/MSI radiometer.

According to conditions \#1 and \#3, it is required to perform field measurements with resolution equal to the minimum MSI radiometer resolution or less. At the same time, with accordance to condition \#2, the measurements should be performed within time interval equaled to the lifetime of phytoplankton distribution or faster. Simultaneous radiometric and water constituents' measurements from a high-speed gliding motorboat completely satisfy these conditions. We used the single Ocean Optics USB2000+ spectrometer to measure the remote sensing reflectance and the ultraviolet fluorescent LiDAR UFL-9 [37] to assess Chl $a$ and TSM concentrations. Both devices were installed on the bow deck (Figure 3). Motorboat length was about $9 \mathrm{~m}$ which, several times, exceeded the length of dominant long waves. In this case, the movement was stable: noticeable pitching and rolling were absent, and ship waves and splashes near the bow did not affect registered signals. While moving with a cruise speed of $8 \mathrm{~m} / \mathrm{s}$, we continuously registered field data with frequencies of $1 \mathrm{~Hz}$ for the spectrometer and $2 \mathrm{~Hz}$ for the LiDAR. This, the spatial data resolutions were equal to $8 \mathrm{~m}$ and $4 \mathrm{~m}$, respectively.

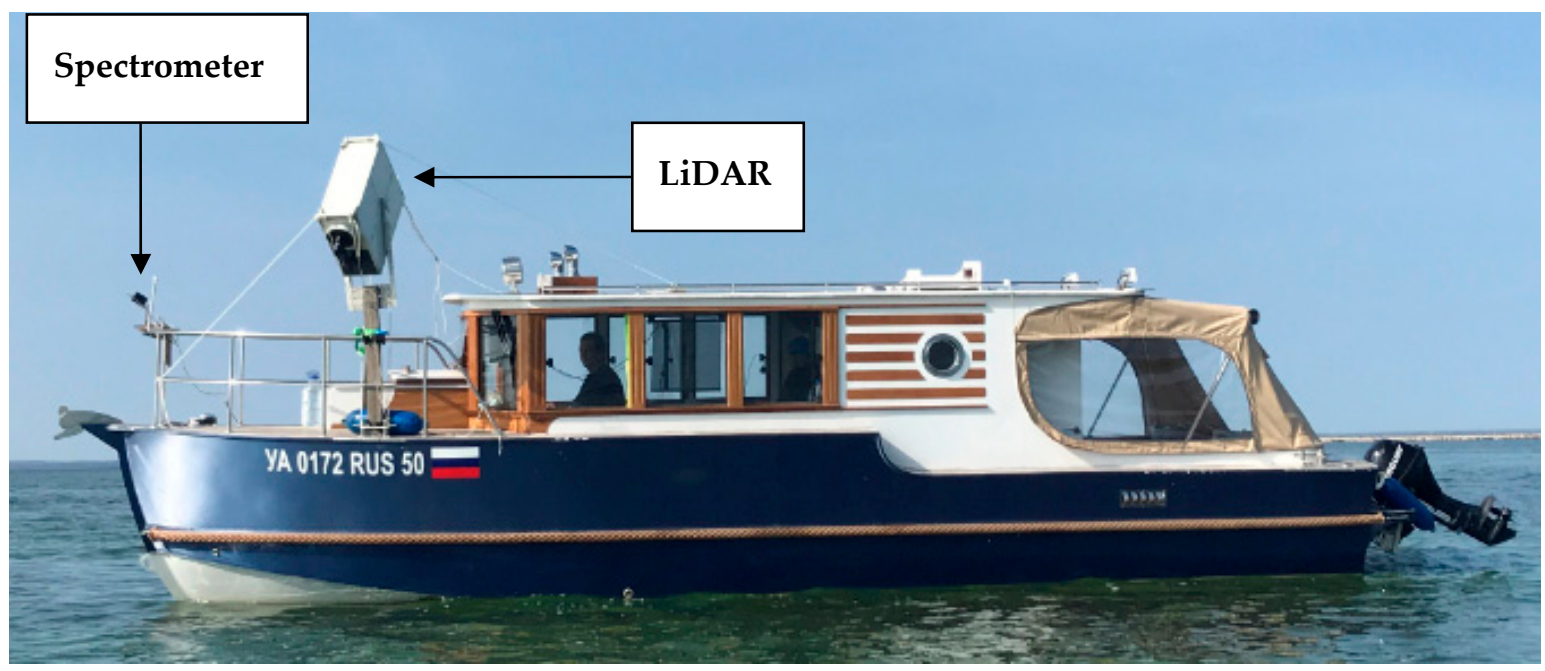

Figure 3. The spectrometer and LiDAR position on a board of the high-speed gliding motorboat.

In situ measurements were carried out from the south side of the reservoir (Figure 4) under Sentinel-2B and MODIS Aqua/Terra overpass on 21 and 22 September 2018, respectively (the results of MODIS images processing are not included in this study). They were performed from 8:00-9:00 UTC. The sky was clear, the weather was sunny. During this time, the Sun azimuth angles and solar elevations varied within $162.8^{\circ}-180.8^{\circ}$ and $33.3^{\circ}-34.5^{\circ}$, respectively (Figure 4 ). Wind waves were smooth (height was about $0.3-0.5 \mathrm{~m}$ ) according to WMO Sea State Code on the first day and calm on the second one. The motorboat route began at the start point, passed along four tracks and ended at the Finish point, which coincides with the start point (Figure 4). Each track was about $6-8 \mathrm{~km}$ and took about 10-15 min, meanwhile, the Sun position changed by azimuth and elevation for $4.5^{\circ}$ and $0.3^{\circ}$, respectively. Therefore, we considered that lighting conditions change slightly. However, to control this assumption, the downwelling irradiance was measured by the spectrometer at the Start and Finish points for each track. Simultaneous measurements of the upwelling radiance and fluorescence signals were performed by the spectrometer and LiDAR, respectively, along each track (details are shown below).

The spectrometer with field-of-view (FOV) of $20^{\circ}$ was installed on the bow railing in the center of the motorboat at the zenith angle of $30^{\circ}$. These conditions were chosen based on the proximity to the requirements of the NASA protocols [38] and practical feasibility. Its azimuth angles were mechanically 
changed to keep the angle of $90^{\circ}$ to the Sun when motorboat changed its track. It was necessary to ensure the constancy of the observation geometry and illumination. The second optical instrument LiDAR with FOV of $1^{\circ}$ was also installed on the bow, slightly behind the spectrometer. It was oriented at an angle of $30^{\circ}$ to the zenith and at $45^{\circ}$ to the motion direction. Such a position of both optical devices was necessary to perform passive optical observations and active laser sensing of the unperturbed water surface in front of motorboat and minimized the falling of splashes and sun glints to the FOV. The motorboat position was registered by onboard Chartplotter Garmin EchoMap 721.

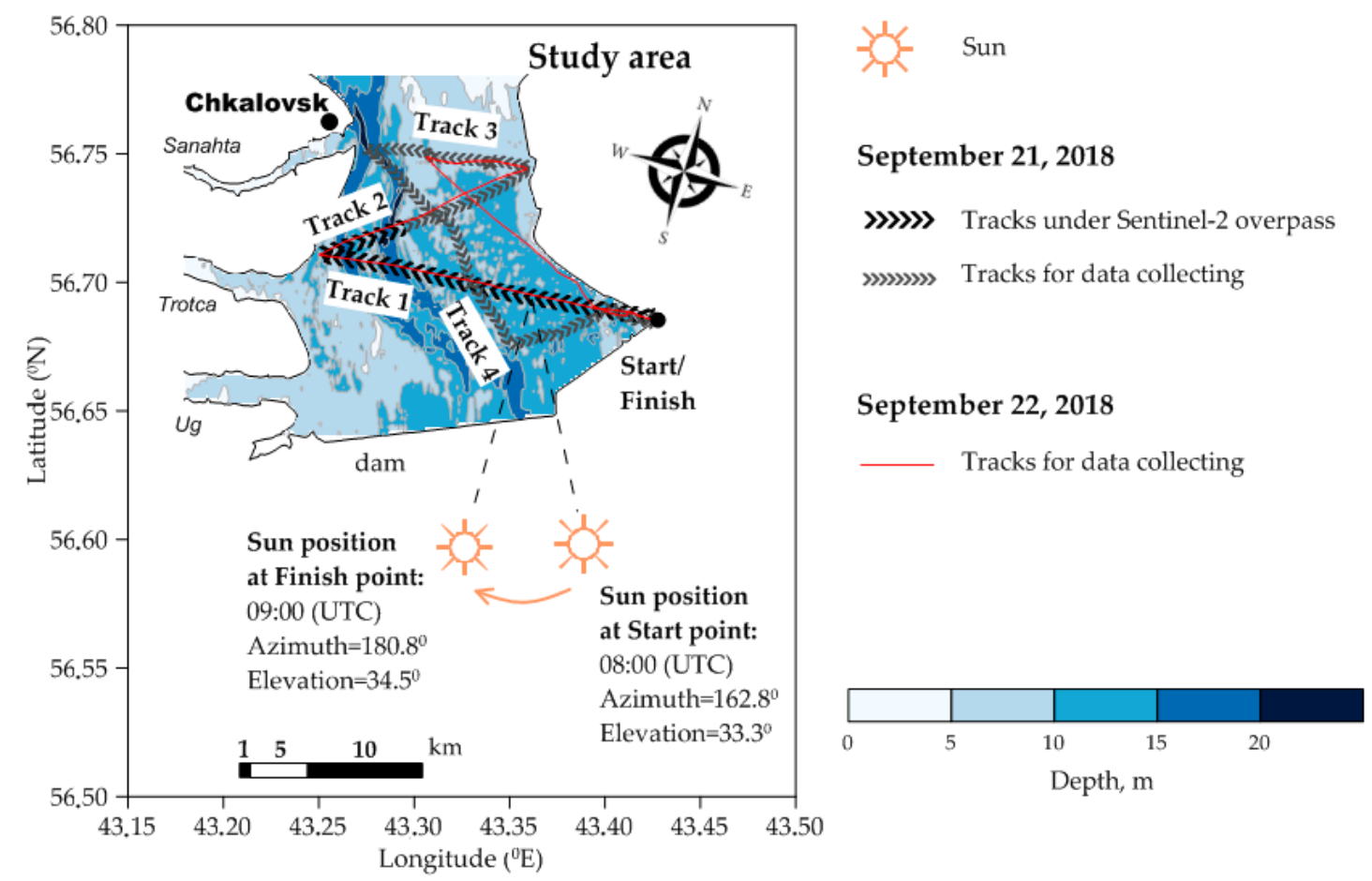

Figure 4. Motorboat route map for 21-22 September 2018.

\subsubsection{Water Sample}

To recalculate fluorescence LiDAR signals to $\mathrm{Chl} a$, and TSM concentration, surface water samples were collected from depth of $0-30 \mathrm{~cm}$ using clear polyethylene bottles at 10 stations. They were delivered to the shore within $1-2 \mathrm{~h}$ in a refrigerator at a temperature of $-4{ }^{\circ} \mathrm{C}$. Filtration was realized through $47 \mathrm{~mm}$ Whatman GF/F fiberglass filters with a pore size of $0.7 \mu \mathrm{m}$ with a low vacuum ( $\sim .2$ bar). Filtered volume was $2 \mathrm{~L}$. Filters were frozen at $-16^{\circ} \mathrm{C}$ and stored under dark conditions for one week. In the laboratory, $\mathrm{Chl} a$ concentration was determined using the spectrophotometric method [39] and calculated according to the equation for mixed phytoplankton [40]. Chlorophyll was extracted in $10 \mathrm{ml}$ of $90 \%$ aqua acetone solution twice during an hour. The extracts were clarified twice by centrifugation for $10 \mathrm{~min}$ at $8000 \mathrm{r} / \mathrm{min}$ speed. Chl $a$ concentration was measured by SF-14 spectrophotometer (Russia), previously calibrated using pure chlorophyll (Sigma) as a standard. Despite the fact that the spectrophotometric method does not satisfy the NASA protocols [41], it is often used to retrieve the concentration of $\mathrm{Chl} a$ as the most accessible method providing reliable accuracy (for example $[24,39,42,43]$ ). Intercomparison of the spectrophotometric method with two others valid by NASA protocols, fluorimetric and high-performance liquid chromatography methods were performed, for example, in [44,45].

TSM concentrations were determined gravimetrically by weight following the drying of filtered samples of known volume on pre-dried and weighed GF/F filters (pore size $0.7 \mu \mathrm{m}$ ), wherein the organic and mineral suspended matter concentrations were obtained by their spectral absorption in accordance with the procedure described in [46]. 


\subsubsection{LiDAR Measurements}

Fluorescence LiDAR systems are widely used around the world for detecting bio-optical parameters of the oceans, seas, and inland waters. Various studies have been conducted on the comparison of LiDAR measurements and satellite data of MODIS, MERIS, and SeaWiFS radiometers in the open seas [47-51]. Especially, LiDAR systems are relevant for small inland waters where spatial patterns of water quality parameters change very fast.

Mentioned LiDAR UFL-9 has been involved in field measurements worldwide: in the Atlantic Ocean, in the Black, the Kara, the Aral, the Caspian, the Baltic, the South China, the Barents, the North, and the Mediterranean Seas, on Lakes Balaton and Issyk-Kul, in the Ikshinsky and the Gorky Reservoirs. Recently, it was used on the Lake Balaton in Hungary, whose geometric dimensions, shape and the water optical properties are similar to the Gorky Reservoir. As a result, high-quality ground-truth LiDAR data were obtained and used for calibration L2 MODIS data [52].

The high quality of the LiDAR data is reached due to its physical principles and technical characteristics. The ultraviolet fluorescence LiDAR UFL-9 analyses returned signal from dual excitation (355 and $532 \mathrm{~nm}$ ) Nd:YAG laser pulses emitted at $2 \mathrm{~Hz}$ with the energy of $2 \mathrm{~mJ}$. Detection is carried out consistently across 11 bands (355, 385, 404, 424, 440, 460, 499, 532, 620, 651, and $685 \mathrm{~nm})$ on stations simultaneously with water sampling for the instrument calibration, and across four bands (355, 404, 440 , and $685 \mathrm{~nm}$ ) simultaneously in transect mode while the motorboat moves. Fluorescence intensities at $440 \mathrm{~nm}(\mathrm{CDOM})$ and $685 \mathrm{~nm}$ (Chl $a)$ and the backscattering signal at $355 \mathrm{~nm}$ (TSM) are normalized to the Raman scattering at $404 \mathrm{~nm}$ and then calibrated using a set of laboratory-measured concentrations of CDOM, Chl $a$, and TSM.

Tested on a great number of water bodies, it allows measuring bio-optical properties with high accuracy for non-contact and express methods. According to [37,52] the total relative measurement error of UFL-9 is 10\% for TSM and CDOM and 16\% for Chl $a$. LiDAR signals processing and its calibration are exhaustively described in [53].

Based on the results of laboratory analysis of water samples, a good correlation between couples "fluorescence signal at $685 \mathrm{~nm}-\mathrm{Chl} a$ concentration" and "backscattered laser signal-TSM concentration" was established (Figure 5):

$$
\begin{gathered}
\text { Chl } a=0.019 \mathrm{x}_{685}^{3.109}, R^{2}=0.91, \\
\mathrm{TSM}=0.06 \mathrm{x}_{355}+5.37, R^{2}=0.64,
\end{gathered}
$$

where $x_{685}$ and $x_{355}$ are the LiDAR signals at $685 \mathrm{~nm}$ and $355 \mathrm{~nm}$ in Raman units, respectively, and $R^{2}$ is the coefficient of determination.

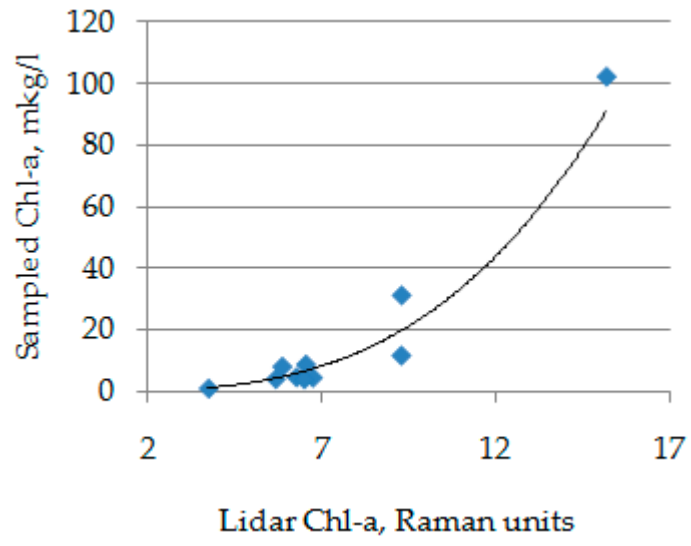

(a)



(b)

Figure 5. Results of comparison of LiDAR signals at stations with lab-analyzed water sample concentrations of (a) Chl $a$, and (b) TSM. Black lines correspond to the best calibration fits (1), and (2), respectively. 


\subsubsection{Radiometric Measurements}

For receiving the water-leaving radiance from above-water measurements it is necessary to measure the total radiance $L_{u}$ and the sky radiance reflected by the water surface $L_{r}$ [54]. Usually, two separate spectrometers are used for registration of these components [55]. However, an approach using a single spectrometer was presented in [56]. The total upwelling radiance $L_{u}$ above the water surface and upwelling radiance $L_{c u v}$ above water-filled cuvette are consequently measured (Figure 6a,b). This cuvette with the sizes of $200 \mathrm{~mm} \times 100 \mathrm{~mm} \times 75 \mathrm{~mm}$ (length $\times$ width $\times$ height) is filled by water to the top. Its walls and bottom absorb $98 \%$ of the incident light. Therefore, the upwelling underwater radiance is considered to be zero, so, $L_{c u v} \approx L_{r}$. Measurements of $L_{u}$ and $L_{r}$ are performed consequently within a few minutes. After that, the water-leaving radiance $L_{w}$ can be obtained as a difference $L_{u}-L_{r}$.

Measurements of the downwelling irradiance $E_{d}$ are usually made by the third spectrometer $[57,58]$. But in our case, $E_{d}$ was estimated through the radiance of the Lambertian surface which was a horizontal plaque $L_{p}$ with known reflection coefficient $R_{p}$ close to Spectralon reflectance standard (Figure 6c). This method is well described in the NASA protocols [38]. The irradiance measurement was performed immediately after $L_{r}$ by the same spectrometer and took a similar time.

Summing up, the proposed method [56] consists in consequent measurement of $L_{u}, L_{r}$, and $L_{p}$ immediately one by one, within a few minutes (Figure $6 a-c)$. This short time interval lets us assume that illumination conditions do not change during measurements.

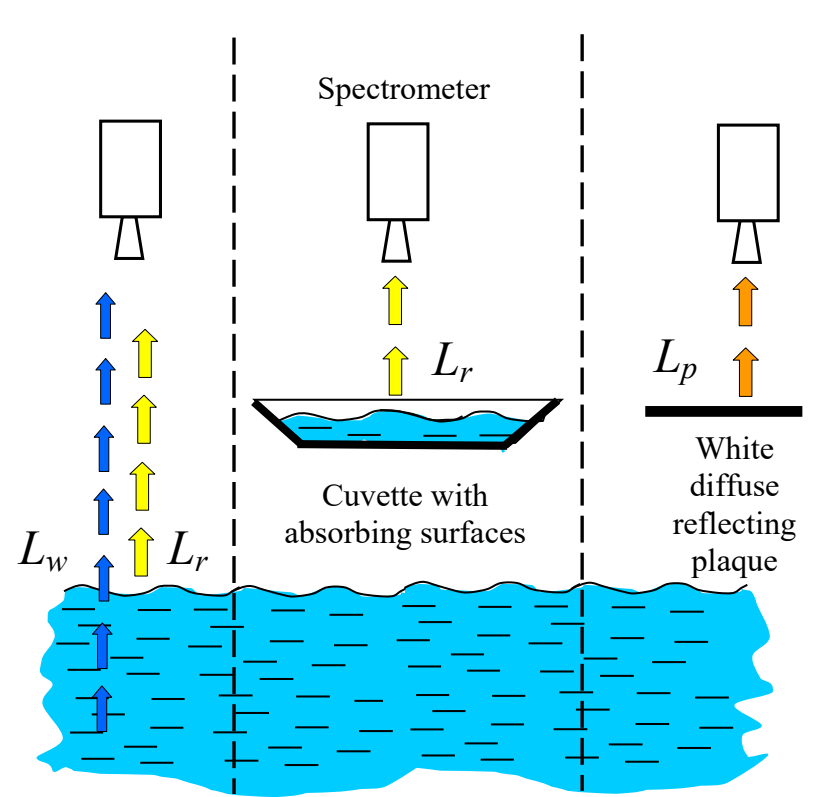

(a)

(b)

(c)

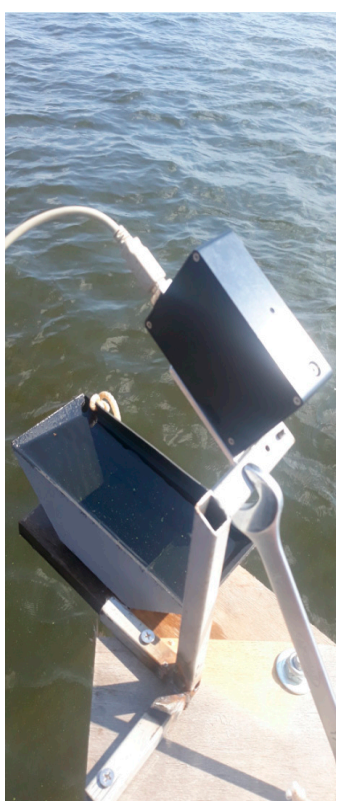

(d)

Figure 6. Schematic explanation of radiometric measurements: (a) the total upwelling radiance, (b) the surface-reflected radiance, and (c) the plaque radiance. Section (d) presents a photo of a water-filled cuvette at field measurements of the surface-reflected radiance.

The obtained time series of $L_{u}, L_{r}$, and $L_{p}$ were averaged and smoothed by the median filter. After that these spectra were converted into $R_{r s}$ similarly to Mobley [54]:

$$
R_{r s}=\frac{L_{u}-L_{r}}{E_{d}}
$$

where $E_{d}=\pi L_{p} / R_{p}$.

The proposed method was used in sea expeditions when the radiometric measurements were performed at ship stops (for example, [59]) or from a stationary oceanographic platform [56]. At the 
same time, this method does not require underwater measurements allowing to apply it while the ship moves.

We modified this approach for continuous ship measurements as follow. The spectral radiances $L_{r}$ and $L_{p}$ were measured in the spectral range of 378-760 $\mathrm{nm}$ with a resolution of $1 \mathrm{~nm}$ by the zenith angle of $30^{\circ}$ with the help of Ocean Optics USB 2000 spectrometer with FOV of $20^{\circ}$. Such observation geometry goes beyond the NASA protocol [38], but not significantly. Therefore, it is often used in ship measurements (for example, [42]). These radiances were registered at the start and finish points of each track (Figure 6d). In our case, it was enough to measure $L_{r}$ and $L_{p}$ at one point for $R_{r s}$ retrieval. However, each track took about 10-15 min on average. Therefore, in order to be sure that illumination conditions are constant, we used averaged spectra of $\bar{L}_{r}$ and $\bar{L}_{p}$ by data from two mentioned points. After that we obtained $R_{r s}$ spectra using the next equation:

$$
R_{r s}=\frac{L_{u}-\bar{L}_{r}}{\bar{E}_{d}}
$$

where $E_{d}=\pi \bar{L}_{p} / R_{p}$.

\subsection{Empirical Models}

\subsubsection{Chl $a$ Models}

Blue-green ratio algorithms [60] are often used to derived Chl $a$ concentration in the open ocean (Case 1 waters), where absorption of phytoplankton pigments mainly affect the water-leaving reflectance. However, in optically-complex water (Case 2 waters) due to the absorption of CDOM and scattering of TSM, they have a poor accuracy [61]. To retrieve Chl $a$ concentration in turbid high-productive waters (eutrophic waters with phytoplankton domination) the NIR-red ratio algorithms are often used $[24,25,61,62]$. These algorithms use band combinations in the range of $665-680$ and $700-710 \mathrm{~nm}$, where water-leaving reflectance maximally and minimally sensitive to the second absorption maximum of phytoplankton pigments, and CDOM influence are negligible.

To develop an empirical Chl $a$ model for the Gorky reservoir, we considered the semi-empirical NIR-red edge algorithms that are popular for optically complex waters: two-band (2B) and three-band (3B) algorithms [24], the Normalized Difference Chlorophyll Index (NDCI) algorithm [25], and the peak height algorithm $(\mathrm{PH})$ [21]. Applied to the central wavelengths of the MSI spectral bands, the indices (band ratio) are as follows:

$$
\begin{gathered}
2 B=R_{r s}(705) / R_{r s}(665), \\
3 B=\left(R_{r s}(665)^{-1}-R_{r s}(705)^{-1}\right) R_{r s}(740), \\
N D C I=\left(R_{r s}(705)-R_{r s}(665)\right) /\left(R_{r s}(705)-R_{r s}(665)\right), \\
P H=R_{r s}(705)-\left(R_{r s}(740)+R_{r s}(665)\right) / 2 .
\end{gathered}
$$

To relate results of usage indices from Equations (5)-(8) with constituent concentrations, linear (linear), 2nd polynomial (poly), exponential (exp), and power (power \#1,\#2) approximations were used:

$$
\mathrm{Chl} a, \mathrm{TSM}=\mathrm{a} \cdot \text { Index }+b,(\text { linear), }
$$

$$
\begin{gathered}
\text { Chl } a, \operatorname{TSM}=\mathrm{a} \cdot \text { Index }{ }^{2}+\mathrm{b} \cdot \text { Index }+c,(\text { poly }), \\
\text { Chl } a, \mathrm{TSM}=\mathrm{a} \cdot \exp \{b \cdot \text { Index }\},(\exp ) \\
\mathrm{Chl} a, \mathrm{TSM}=\mathrm{a} \cdot \text { Index }^{b},(\text { power \#1) } \\
\text { Chl } a, \mathrm{TSM}=(\mathrm{a} \cdot \text { Index }+b)^{c},(\text { power \#2) }
\end{gathered}
$$


where Index denotes the MSI indices from Equations (5)-(8).

\subsubsection{TSM Models}

TSM concentration is an important indicator of water quality, as well as Chl $a$, especially for reservoirs with significant river discharges, coastal erosion, and sediment resuspension. To retrieve TSM concentration in optically complex waters, satellite bands in the red and NIR ranges are often used [26,63-65]. The widespread single-band algorithms use features of the reflectance spectrum in the red region and near the reflectance peaks at 560 and $810 \mathrm{~nm}$. Most of these algorithms were obtained for sediment-rich waters, where water constituents significantly differ from those in highly productive waters of the Gorky Reservoir. It was found that TSM concentration strongly correlates with Chl $a$ concentration (coefficient of correlation $\mathrm{r}$ 0.85) in our study area. Consequently B4 band (665 nm) of Sentinel-2/MSI will not be optimal for retrieval of TSM concentration due to strong absorption of phytoplankton pigments and phycocyanin fluorescence in the red region. Therefore, various single-band and band-ratio models of TSM in the form of Equations (9)-(13) were considered. B3 and B5 bands associated with reflectance maxima at 560 and $705 \mathrm{~nm}$ were used for single-band models, as well as B6 (740 $\mathrm{nm})$.

\subsection{Satellite Data}

One Sentinel-2B (L1C) MSI image was downloaded from the Sentinels Scientific Data Hub [66]. The time of satellite acquisition 09/21/2019 was 08:29 UTC and coincided with the time of field measurements (from 08:00-09:00 UTC). To obtain L2 products we considered the next software for the processing of Sentinel-2 images: SeaDAS, ACOLITE, C2RCC, iCOR, and Sen2Cor.

The SeaDAS [67] is a reliable atmosphere correction (AC) tool suitable for many ocean color sensors. The usage of the AC and vicarious calibration for Sentinel-2 is fully described in [14] and opens up the possibility to retrieve $R_{r s}$ spectra with high accuracy. The AC for OLI "lite" (ACOLITE) is a processing software developed for aquatic applications of high-resolution Landsat (5/7/8) and Sentinel-2 (A/B) data [68]. It allows the retrieval of the water reflectance on the bottom of the atmosphere and was used to solve various tasks [69-71]. The SeNtinel Application Platform (SNAP) software package provides several tools for processing Sentinel-2 images and supports the installation of external plugins. We considered C2RCC [72], iCOR [73] and Sen2Cor [74], used for study of inland waters in [17,19].

Sentinel data were resampled on the resolution of $20 \mathrm{~m}$. On the average, two of three in situ measurements were fallen in one $20 \mathrm{~m}$ pixel. To reduce the difference between inhomogeneous of in situ data and averaged satellite product, the match-up data were smoothed with a cosine filter.

\subsection{Accuracy Assessment}

Evaluating the models performance were done based upon three statistical metrics:

$$
\begin{aligned}
\text { RMSE } & =\sqrt{\frac{1}{N} \sum_{i=1}^{N}\left(y_{i}-y_{i}^{m}\right)^{2},} \\
M A P E & =\frac{1}{N} \sum_{i=1}^{N} \frac{\left|y_{i}-y_{i}^{m}\right|}{y_{i}^{m}} \cdot 100, \\
\text { Bias } & =\frac{1}{N} \sum_{i=1}^{N}\left(y_{i}-y_{i}^{m}\right) .
\end{aligned}
$$

where $y_{i}$ and $y_{i}^{m}$ are the predicted and measured values. 


\section{Results}

\subsection{Statistics of Chl $a$ and TSM Variations}

Descriptive statistics of $21502 \mathrm{Chl} a$ and TSM measurements per two days are given in Table 2. Here. $\mathrm{N}$ is a number of measurements; Min, Max, and Mean are the minimum, maximum and average values respectively; Median is the median; STD is the standard.

Despite the fact that measurements were performed on closed transects for 2 days (Figure 4), the daily variability of Chl $a$ and TSM concentrations was great. On the second day, the concentration of $\mathrm{Chl} a$ and TSM increased by factors of 4 and 1.5, respectively. In some places, the maximum of Chl $a$ concentration reached a value of $463.4 \mathrm{mg} / \mathrm{m}^{3}$. These variations were associated with the changes in the water surface state. According to the meteorological archive [36], the first day of measurement was the last day of prolonged wind forcing of the western direction. In that morning, surface roughness was characterized by waves with an average height of $0.3-0.5 \mathrm{~m}$ (in opposition to $0.5-1.0 \mathrm{~m}$ in the previous days). In the evening the roughness was completely damped. As a result, in the morning of the second day of measurements, phytoplankton concentrated in the thin near-surface water layer and formed strong heterogeneous structures with different scales, starting from a few meters. These structures were observed during all day long due to calm weather.

Table 2. Statistics of Chl $a$ and TSM concentrations measured on 21 September 2018 and 22 September 2018.

\begin{tabular}{|c|c|c|c|c|c|c|}
\hline Parameter & $\mathbf{N}$ & Min & $\operatorname{Max}$ & Mean & Median & STD \\
\hline \multicolumn{7}{|c|}{21 September 2018} \\
\hline Chl $a\left(\mathrm{mg} / \mathrm{m}^{3}\right)$ & 15,545 & 0.45 & 96.94 & 15.57 & 13.25 & 10.88 \\
\hline $\mathrm{TSM}(\mathrm{mg} / \mathrm{L})$ & 15,545 & 5.00 & 26.77 & 5.87 & 5.88 & 1.10 \\
\hline \multicolumn{7}{|c|}{22 September 2018} \\
\hline Chl $a\left(\mathrm{mg} / \mathrm{m}^{3}\right)$ & 5957 & 4.26 & 463.42 & 57.41 & 38.77 & 52.48 \\
\hline $\mathrm{TSM}(\mathrm{mg} / \mathrm{L})$ & 5957 & 5.38 & 38.76 & 8.42 & 6.54 & 4.39 \\
\hline
\end{tabular}

\subsection{Reflectance Spectra}

A total of $6020 R_{r s}$ spectra were obtained per two days. Its examples for Chl $a$ concentration varied from $0-100 \mathrm{mg} / \mathrm{m}^{3}$ are shown in Figure 7a. These spectra are typical for inland water with dominant cyanobacteria bloom [60-63]. The absorption maxima of phytoplankton and CDOM in the blue region well expressed. Two peaks at $560-570 \mathrm{~nm}$ and $710-720 \mathrm{~nm}$ are associated with scattering on suspended particles (organic and mineral) and with total absorption minimum. Local minimum at 620-630 nm and 670-680 nm are caused by absorption of phycocyanin (PC) and phytoplankton, respectively. A peak at $640-660 \mathrm{~nm}$ is associated with PC fluorescence.

In some points on the reservoir with $\mathrm{Chl} a>100 \mathrm{mg} / \mathrm{m}^{3}$, reduction of $R_{r s}$ at $740-760 \mathrm{~nm}$ due to water absorption was weak or absent (Figure $7 b$ ). Such spectra corresponded to floating algae or surface accumulation (surface scum, dense mats) showed in Figure 1c. Empirical models for these areas should be developed separately. Therefore, 1993 spectra approaching to the vegetation spectrum were excluded. The ratio $\operatorname{Rrs}(755) / \operatorname{Rrs}(705) \geq 0.9$ was used as a criterion for exclusion. 


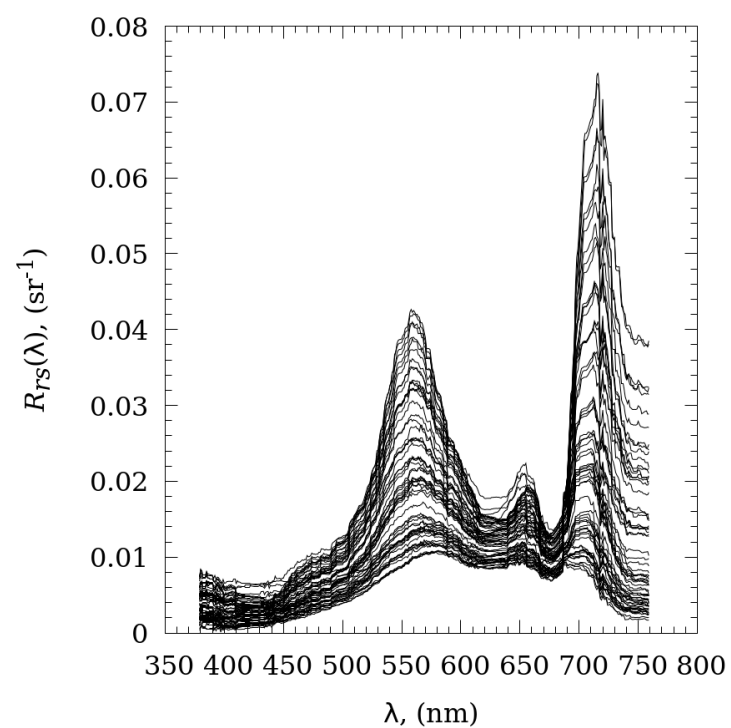

(a)

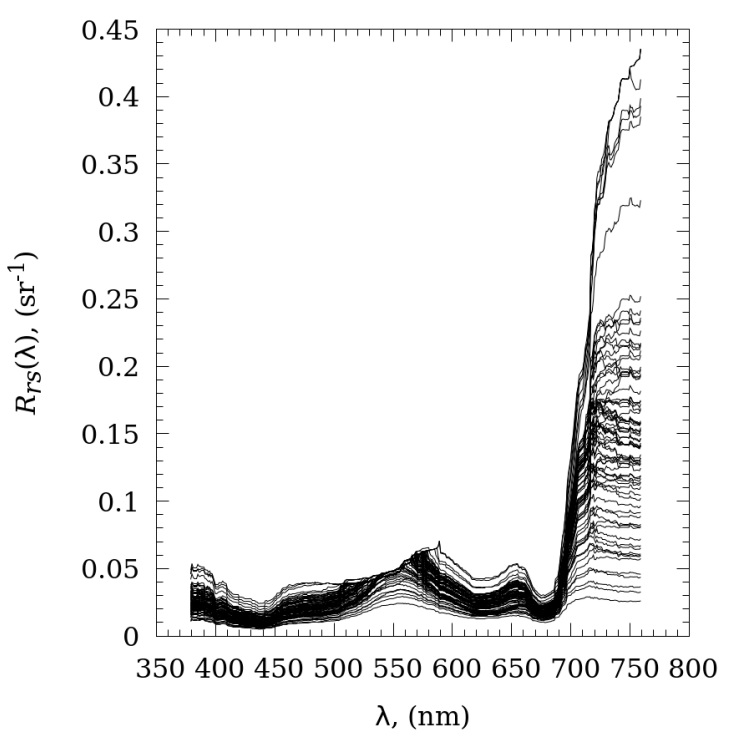

(b)

Figure 7. Examples of $R_{r s}$ spectra measured in the Gorky reservoir for two days: (a) spectra included in the temporal-synchronous dataset for calibration/validation of empirical models; and (b) spectra excluded from calibration/validation dataset.

\subsection{In Situ Dataset}

Two datasets, including 21,502 LiDAR and 6020 radiometric measurements, were used for the composition of the combined dataset.

LiDAR continuously registered fluorescent signals, including the motorboat stops between tracks, while the continuous recording of the upwelling radiance by the spectrometer was interrupted for measurements of water surface radiance and downwelling irradiance. In addition, these optical instruments had different temporal resolutions: $2 \mathrm{~Hz}$ for the LiDAR and $1 \mathrm{~Hz}$ for the spectrometer. As a result, we obtained two datasets with different dimension. Using averaging of the LiDAR data over one second, and temporal synchronization of two datasets, the combined dataset including 6020 measurements per two days with a spatial resolution of $8 \mathrm{~m}$ was collected. After that, 1933 values corresponding to excluded $R_{r s}$ spectra were excluded, too. The resulting dataset including $4087 \mathrm{Chl} a$ and TSM concentrations (Table 3), as well as $R_{r s}$ spectra were used for the development of regional empirical models for $\mathrm{Chl} a$ and TSM estimation. For this purpose, $60 \%$ of this dataset were randomly selected for models calibration, and the remaining $40 \%$ for its validation. For the creation of $\mathrm{Chl} a$ and TSM retrieval algorithms by Sentinel- 2 imagery, we used only a certain part of this dataset, including 671 measurements which were maximally close to the satellite overpass (within $10 \mathrm{~min}$ ). These data corresponded to measurements at the first and half second tracks marked by an arrow line in Figure 4 . As before, $60 \%$ of this dataset were randomly selected for model calibration and the remaining $40 \%$ for its validation.

Table 3. Statistics of temporal-synchronous dataset used for the development of empirical models.

\begin{tabular}{ccccccc}
\hline Parameter & N & Min & Max & Mean & Median & STD \\
\hline Chl $a\left(\mathrm{mg} / \mathrm{m}^{3}\right)$ & 4087 & 1.06 & 99.32 & 29.85 & 27.11 & 18.37 \\
TSM $(\mathrm{mg} / \mathrm{L})$ & 4087 & 5.00 & 19.48 & 6.55 & 5.88 & 1.65 \\
\hline
\end{tabular}

To develop empirical models for estimation of Chl $a$ and TSM concentration, and assess AC accuracy, the hyperspectral radiometric data were resampled in Sentinel-2B/MSI bands to obtain the simulated remote sensing reflectance $R_{r s}(\lambda)$ as: 


$$
R_{r s}(\lambda)=\int_{\lambda_{1}}^{\lambda_{2}} S R F(\lambda) R_{r s}^{m e a s}(\lambda) d \lambda / \int_{\lambda_{1}}^{\lambda_{2}} S R F(\lambda) d \lambda
$$

where $\operatorname{SRF}(\lambda)$ is the spectral response function of Sentinel-2B/MSI; $R_{r s}^{\text {meas }}(\lambda)$ are in situ hyperspectral radiometric data; and $\lambda_{1}$ and $\lambda_{2}$ are the lower and upper wavelengths of the MSI spectral band. Further, they were overlapped on the satellite image and averaged pixel-by-pixel.

\subsection{Calibration and Validation of Empirical Models}

\subsubsection{Chl $a$ Models}

Accuracy assessment for different empirical models on the basis of the calibration dataset $(\mathrm{N}=2452$, $60 \%)$ and the validation dataset $(\mathrm{N}=1635,40 \%)$ are presented in Table 4 . The exponential Chl $a$ models for all indices gave the most inaccurate prediction of $\mathrm{Chl} a$ concentration (MAPE $=45-74 \%$ and Bias $\left.=0.15-0.77 \mathrm{mg} / \mathrm{m}^{3}\right)$. The power $2 \mathrm{~B}$ and $\mathrm{PH}$ models showed the highest values of Bias $(0.27$ and $-0.13 \mathrm{mg} / \mathrm{m}^{3}$ ). Among other models, it was difficult to select the best one because of the closeness of their efficiency parameters. The power and polynomial $2 \mathrm{~B}$ models gave approximately the same estimates $\left(R M S E=9.76 \mathrm{mg} / \mathrm{m}^{3} ; M A P E=40.6 \%\right.$ and $M A P E=41.6 \% ;$ Bias $=0.05 \mathrm{mg} / \mathrm{m}^{3}$ and Bias $\left.=0.02 \mathrm{mg} / \mathrm{m}^{3}\right)$. The linear 2B model had slightly lower accuracy $(M A P E=44.16 \%)$, but could also be used. The power 3B model [61] had better parameters $\left(R M S E=9.33 \mathrm{mg} / \mathrm{m}^{3} ; M A P E=39.0 \% ;\right.$ Bias $\left.=0.02 \mathrm{mg} / \mathrm{m}^{3}\right)$ than the linear and polynomial 3B models due to more accurate fitting for $\mathrm{Chl} a>80 \mathrm{mg} / \mathrm{m}^{3}$. In addition, this model showed the lowest RMSE among all models. The power \#2 and the polynomial NDCI models had the same RMSE and MAPE as similar 2B models, however, their Bias is smaller. At the same time, the polynomial NDCI model overestimates forecasts, but the power model underestimates it. RMSE and Bias of the linear NDCI models are slightly higher but its MAPE of $37.1 \%$ is the lowest among all investigated models. For $\mathrm{PH}$, the polynomial and the power \#2 models gave the best results, but their efficiency parameters are worse than NIR-red edge models. The best models for each index are marked in bold in Table 4.

Table 4. Calibration and validation results of $\mathrm{Chl} a$ models. All parameters were derived from the calibration dataset $(\mathrm{N}=2452,60 \%)$ and the validation dataset $(\mathrm{N}=1635,40 \%)$.

\begin{tabular}{|c|c|c|c|c|c|c|c|c|}
\hline \multirow[b]{2}{*}{ Index } & \multicolumn{4}{|c|}{ Calibration } & \multicolumn{4}{|c|}{ Validation } \\
\hline & $R^{2}$ & $a$ & $b$ & $c$ & $R M S E\left(\mathrm{mg} / \mathrm{m}^{3}\right)$ & MAPE (\%) & Bias $\left(\mathrm{mg} / \mathrm{m}^{3}\right)$ & Fits \\
\hline \multirow{5}{*}{$2 B$} & 0.71 & 24.463 & -8.356 & - & 9.86 & 44.1 & 0.03 & linear \\
\hline & 0.71 & -2.155 & 33.034 & -15.59 & 9.76 & 41.6 & 0.02 & poly \\
\hline & 0.62 & 12.546 & 0.526 & - & 11.19 & 60.5 & 0.59 & $\exp$ \\
\hline & 0.70 & 17.346 & 1.198 & - & 9.98 & 47.9 & 0.27 & power \#1 \\
\hline & 0.71 & 96.806 & -61.71 & 0.764 & 9.76 & 40.6 & -0.05 & power \#2 \\
\hline \multirow{4}{*}{$3 \mathrm{~B}$} & 0.68 & 35.812 & 19.24 & - & 10.26 & 53.6 & 0.06 & linear \\
\hline & 0.73 & -10.227 & 52.867 & 16.91 & 9.54 & 46.6 & 0.07 & poly \\
\hline & 0.49 & 25.114 & 0.554 & - & 12.72 & 74.4 & 0.77 & $\exp$ \\
\hline & 0.74 & 4373.068 & 296.6 & 0.479 & 9.33 & 39.0 & 0.02 & power \#2 \\
\hline \multirow{4}{*}{ NDCI } & 0.69 & 90.101 & 13.75 & - & 10.13 & 37.1 & -0.02 & linear \\
\hline & 0.71 & 88.757 & 52.715 & 15.06 & 9.79 & 41.9 & 0.01 & poly \\
\hline & 0.71 & 16.365 & 2.754 & - & 9.83 & 45.2 & 0.15 & $\exp$ \\
\hline & 0.71 & 6.251 & 3.359 & 2.217 & 9.80 & 40.4 & -0.01 & power \#2 \\
\hline \multirow{5}{*}{$\mathrm{PH}$} & 0.69 & 2340.123 & 9.185 & - & 10.12 & 47.4 & -0.02 & linear \\
\hline & 0.69 & -17567.0 & 2814.313 & 7.11 & 10.06 & 45.4 & -0.03 & poly \\
\hline & 0.62 & 17.808 & 52.313 & - & 11.21 & 60.8 & 0.41 & $\exp$ \\
\hline & 0.69 & 890.568 & 0.708 & - & 10.06 & 42.9 & -0.13 & power 1 \\
\hline & 0.69 & 7834.173 & 8.051 & 0.789 & 10.05 & 44.8 & 0.02 & power 2 \\
\hline
\end{tabular}


Despite the fact that most of the models explain about $70 \%$ of the variation of $\mathrm{Chl} a$ concentration $\left(R^{2} \sim 0.7\right)$, and $R M S E \sim 9-10 \mathrm{mg} / \mathrm{m}^{3}$, all of them cannot be considered as models with high prediction accuracy $(M A P E \geq 40 \%)$. Perhaps this result is due to insufficient consistency of radiometric and LiDAR data (Figure 8a) produced by two reasons. The first one is different footprints on the water surface: $0.4 \mathrm{~m}^{2}$ for the spectrometer and $0.02 \mathrm{~m}^{2}$ for the LiDAR. The second one is its shifting from each other to $1.5 \mathrm{~m}$. Thus, these instruments scan different parts of the water surface. As a result, the difference between radiometric and LiDAR signals (Figure 8a) could lead to a significant scattering in the synchronous dataset used for calibration and validation of models (Figure 8b,c).

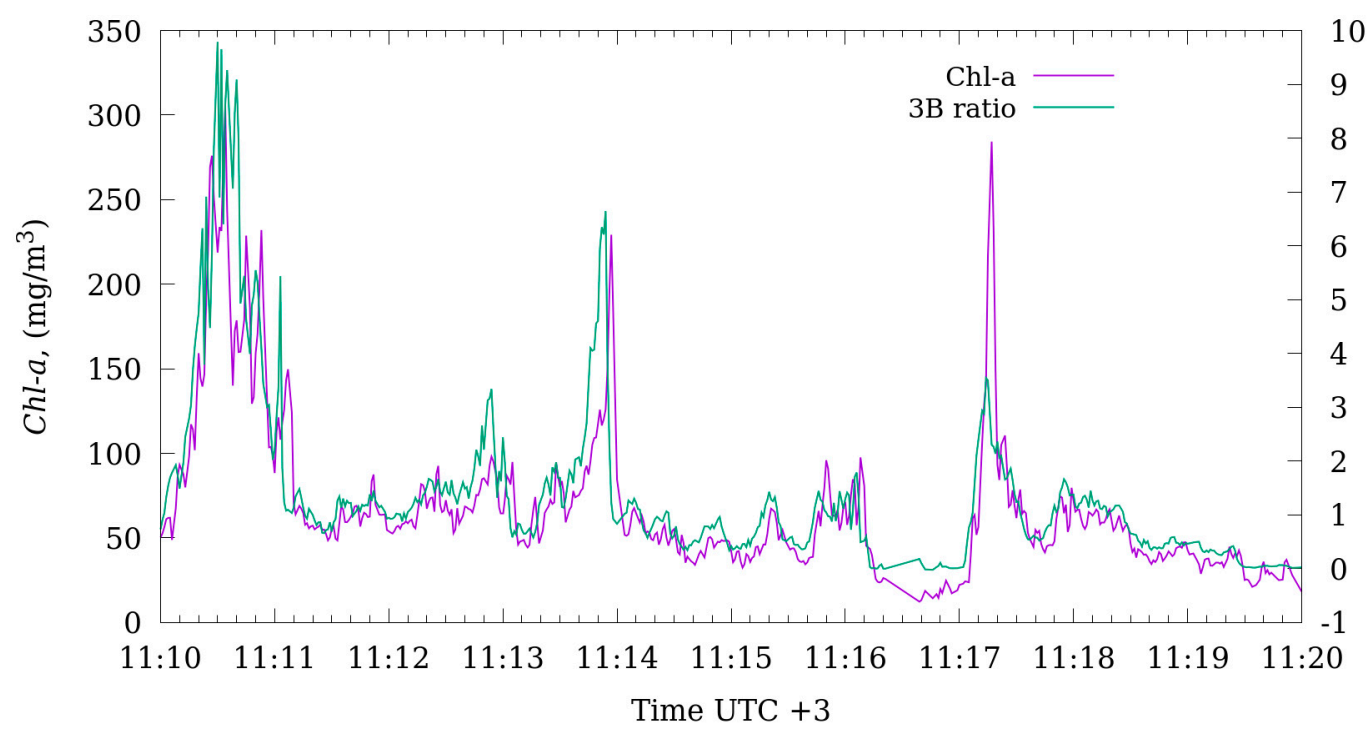

(a)



(b)

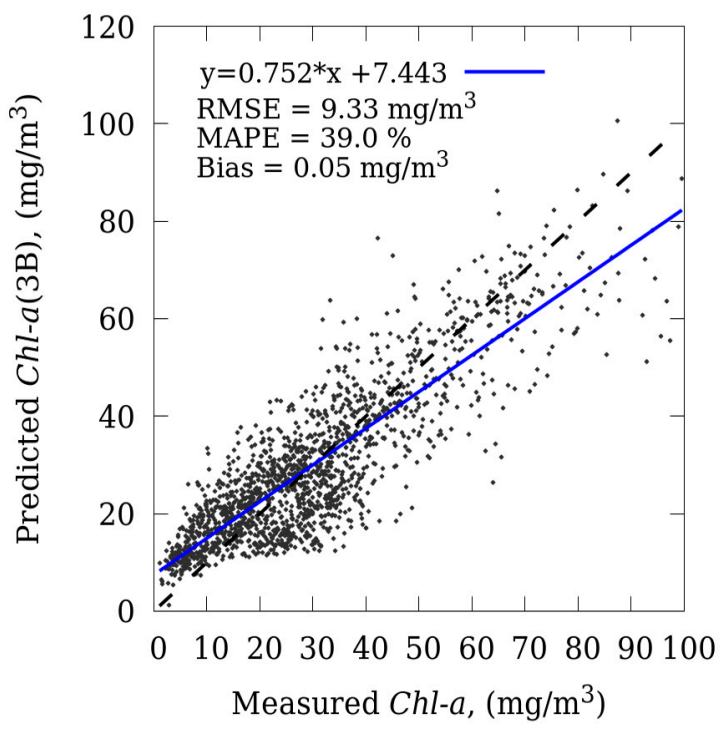

(c)

Figure 8. (a) Fragment $(\mathrm{N}=520)$ of time-series of $\mathrm{Chl} a$ and $3 \mathrm{~B}$ ratio calculated by radiometric measurements of 22 September 2018. Three-band model (3B) for estimation of Chl $a$ concentration using bands 4,5,6 of MSI/Sentinel-2: (b) the results of calibration $(\mathrm{N}=2452)$; and (c) the results of validation $(\mathrm{N}=1635)$ of the 3B model. The dashed line on $(\mathrm{c})$ represents the 1:1 line.

Furthermore, it should be noted that the calibration coefficients for all models were significantly lower in comparison with $[24,25,61,62]$, possibly due to features of the hydro-optical water properties 
of the Gorky Reservoir. However, the calibration coefficients of the linear PH model $(y=2231 x+12.7$; $R^{2}=0.80$ ) obtained in [19] were quite close to those obtained in our research.

\subsubsection{TSM Models}

Calibration and validation of these models were carried out using the same dataset (Table 3). Their efficiency was evaluated according to Equations (14)-(16). The main results are shown in Table 5.

The single-band algorithms in Table 5 showed a high correlation $\left(R^{2}>0.7\right)$. B3, B5, and B6 bands provided good efficiency. Among the models based on $R_{r s}$ maximum, B3 polynomial and B5 exponential ones were more accurate. However, the B6 polynomial model (marked bold in Table 5) showed the highest coefficient of determination $\left(R^{2}=0.75\right)$ and the prediction accuracy $(R M S E=0.60 \mathrm{mg} / \mathrm{L}$; $M A P E=6.13 \%$; Bias $=-0.001 \mathrm{mg} / \mathrm{L})($ Figure $9 \mathrm{a}, \mathrm{b})$. Probably, this is due to the absorption by CDOM and phytoplankton pigments at $740-760 \mathrm{~nm}$ is negligible and water-leaving radiance is mainly determined by the absorption of pure water and scattering on suspended particles. For this reason, we think that B6-based models are more reliable.

Table 5. Calibration and validation results of TSM models. All parameters were derived from the calibration dataset $(\mathrm{N}=2452)$ and the validation dataset $(\mathrm{N}=1635)$.

\begin{tabular}{|c|c|c|c|c|c|c|c|c|}
\hline \multirow[b]{2}{*}{ Index } & \multicolumn{4}{|c|}{ Calibration } & \multicolumn{4}{|c|}{ Validation } \\
\hline & $R^{2}$ & $a$ & $b$ & $c$ & $R M S E(\mathrm{mg} / \mathrm{L})$ & MAPE (\%) & Bias (mg/L) & Fits \\
\hline \multicolumn{9}{|c|}{ Single band algorithms } \\
\hline \multirow{4}{*}{ B3 } & 0.69 & 141.339 & 3.949 & - & 0.68 & 7.20 & -0.008 & linear \\
\hline & 0.71 & 2277.23 & 42.359 & 4.85 & 0.66 & 6.49 & -0.001 & poly \\
\hline & 0.71 & 4.437 & 20.386 & - & 0.66 & 6.69 & -0.004 & $\exp$ \\
\hline & 0.64 & 26.494 & 0.348 & & 0.75 & 7.86 & -0.057 & power \#1 \\
\hline \multirow{4}{*}{ B5 } & 0.71 & 90.735 & 4.646 & - & 0.66 & 6.48 & -0.006 & linear \\
\hline & 0.71 & 149.813 & 82.16 & 4.734 & 0.76 & 7.76 & -0.376 & poly \\
\hline & 0.70 & 4.98 & 12.356 & - & 0.67 & 6.39 & 0.002 & $\exp$ \\
\hline & 0.65 & 18.071 & 0.257 & & 0.74 & 7.62 & -0.060 & power \#1 \\
\hline \multirow{4}{*}{ B6 } & 0.74 & 122.89 & 5.27 & - & 0.63 & 6.21 & 0.006 & linear \\
\hline & 0.75 & -871.689 & 157.24 & 5.103 & 0.60 & 6.13 & -0.001 & poly \\
\hline & 0.70 & 5.509 & 15.105 & - & 0.70 & 6.89 & 0.016 & $\exp$ \\
\hline & 0.64 & 14.838 & 0.170 & - & 0.73 & 7.85 & -0.056 & power \#1 \\
\hline \multicolumn{9}{|c|}{ Band ratio algorithms } \\
\hline \multirow{3}{*}{ B3/B4 } & 0.66 & 3.127 & 1.857 & - & 0.72 & 6.93 & -0.026 & linear \\
\hline & 0.69 & 1.495 & -1.631 & 5.449 & 0.69 & 6.16 & -0.018 & poly \\
\hline & 0.68 & 3.213 & 0.466 & - & 0.70 & 6.51 & -0.020 & $\exp$ \\
\hline \multirow{3}{*}{ B5/B4 } & 0.68 & 1.683 & 3.751 & - & 0.69 & 6.48 & -0.022 & linear \\
\hline & 0.68 & 0.143 & 1.128 & 4.213 & 0.69 & 6.16 & -0.019 & poly \\
\hline & 0.68 & 4.341 & 0.239 & - & 0.69 & 6.09 & -0.015 & $\exp$ \\
\hline \multirow{3}{*}{ B6/B5 } & 0.62 & 8.032 & 3.119 & - & 0.74 & 8.93 & -0.008 & linear \\
\hline & 0.71 & 16.955 & -7.345 & 6.306 & 0.64 & 6.78 & 0.014 & poly \\
\hline & 0.67 & 3.79 & 1.251 & - & 0.69 & 8.25 & -0.006 & $\exp$ \\
\hline \multirow{3}{*}{$\mathrm{PH}$} & 0.66 & 160.207 & 4.96 & - & 0.72 & 6.62 & -0.016 & linear \\
\hline & 0.66 & 788.31 & 139.449 & 5.048 & 0.71 & 6.45 & -0.015 & poly \\
\hline & 0.66 & 5.167 & 22.503 & - & 0.72 & 6.40 & -0.011 & $\exp$ \\
\hline
\end{tabular}




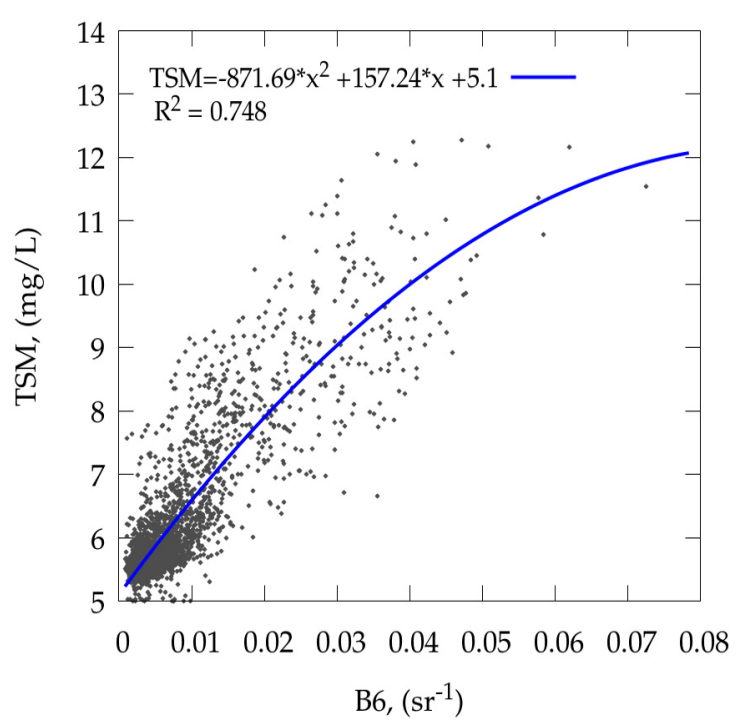

(a)



(c)

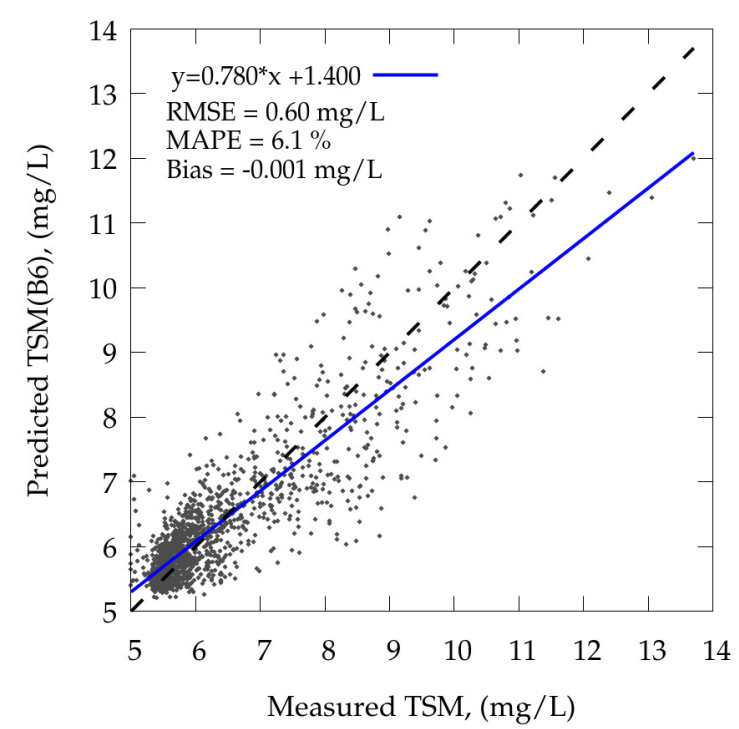

(b)

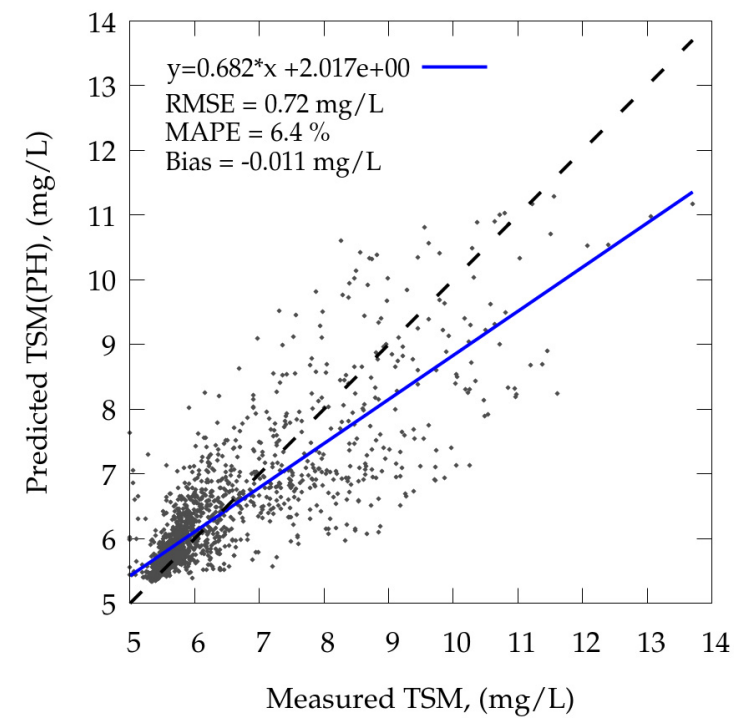

(d)

Figure 9. One-band model for TSM estimation using B6 band of MSI/Sentinel-2: (a) results of calibration $(\mathrm{N}=2452)$ and $(\mathbf{b})$ results of validation $(\mathrm{N}=1635)$; band-ratio model for estimation of TSM concentration using a height of the reflectance peak near $710 \mathrm{~nm}(\mathrm{PH})$ calculated by B4, B5, B6 bands of MSI/Sentinel-2: (c) results of calibration $(\mathrm{N}=2452)$ and $(\mathrm{d})$ results of validation $(\mathrm{N}=1635)$. Dashed line represents 1:1 line.

We also considered band ratio models using bands corresponding to the minimum and maximum absorption, and the peak at $705 \mathrm{~nm}$. Despite the fact that B2 and B4 single-band models showed the same accuracy of TSM retrieval, B3/B2 and B3/B4 models showed different efficiency. In particular, coefficients of correlation $r$ were 0.45 (not shown) and 0.82 , respectively, which confirms the unsuitability of the blue-green band ratio algorithms for optically complex waters even in the presence of covariance between TSM and Chl $a$ concentrations. At the same time, it was difficult to determine the best algorithm because the all band ratios presented in Table 5 have similar statistical parameters. We have marked italic one algorithm for each index. Finally, PH models were slightly worse relative to other band-ratio algorithms and, therefore, it can also be used to predict TSM concentrations (Figure 9c,d). 


\subsection{Atmospheric Correction}

The aerosol radiance due to scattering by aerosols has been greatly overestimated when the Sentinel-2 image was processed in $12 \mathrm{gen}$ (SeaDAS). As a result, retrieved $R_{r s}$ spectra were negative at all wavelengths. Therefore, we were unable to use this processing tool in our study. Examples of retrieved $R_{r s}$ spectra obtained by ACOLITE, C2RCC, and Sen2Cor are shown in Figure 10. In our case, the C2RCC algorithm, using neural network technologies, could not predict the shape of the spectral curve. At the same time, the magnitude of $R_{r s}$ was one order less than the measured one. Such difference from [5] may be related to different water optical properties of the Estonian lakes $\left(\rho_{w}(560)=0.003-0.02\right.$, $\left.R_{r s}=0.001-0.0065 \mathrm{sr}^{-1}\right)$ and the Gorky Reservoir $\left(\rho_{w}=0.04-0.11 ; R_{r s}=0.013-0.035 \mathrm{sr}^{-1}\right)$. Two other plugins, ACOLITE and Sen2Cor, provided similar $R_{r s}$ spectra. Usually, they were lower than measured ones, excepting blue bands where Sen2Cor gave much higher values. The adjacency effects at $740 \mathrm{~nm}$ also appeared the same. The iCOR (not shown) did not reproduce the spectral shape: there was no decrease at $665 \mathrm{~nm}$ and $R_{r s}$ values at B1-B5 bands were similar. In addition, iCOR had no pixel geolocation, which made it impossible for usage.

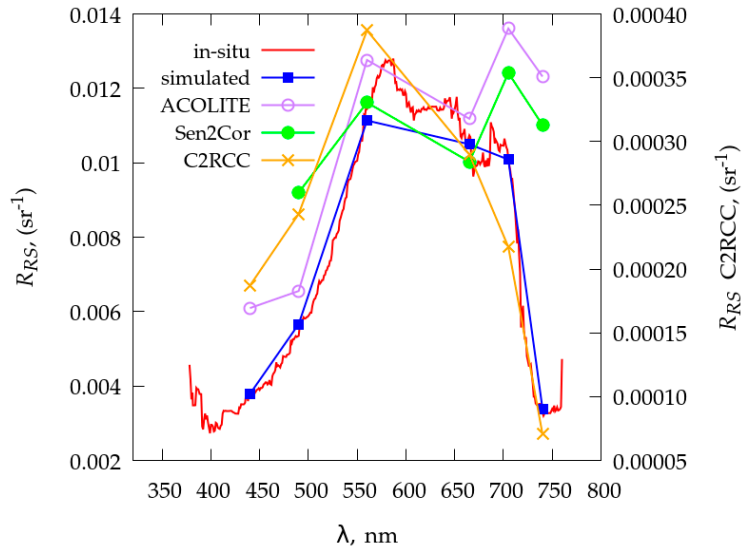

(a)

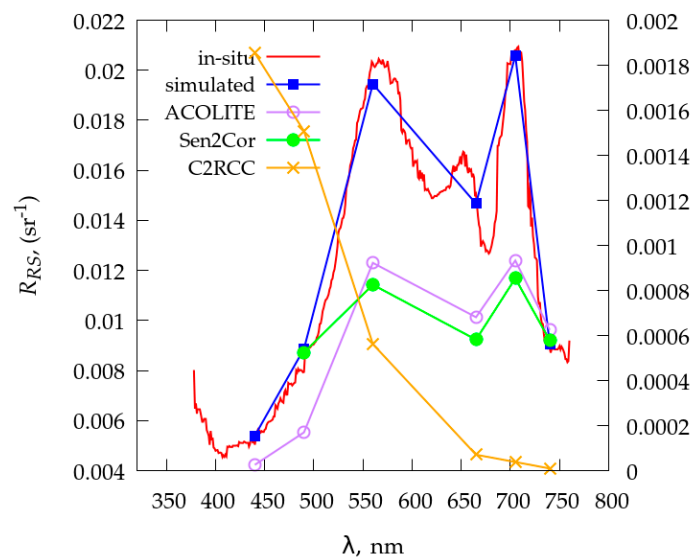

(c)

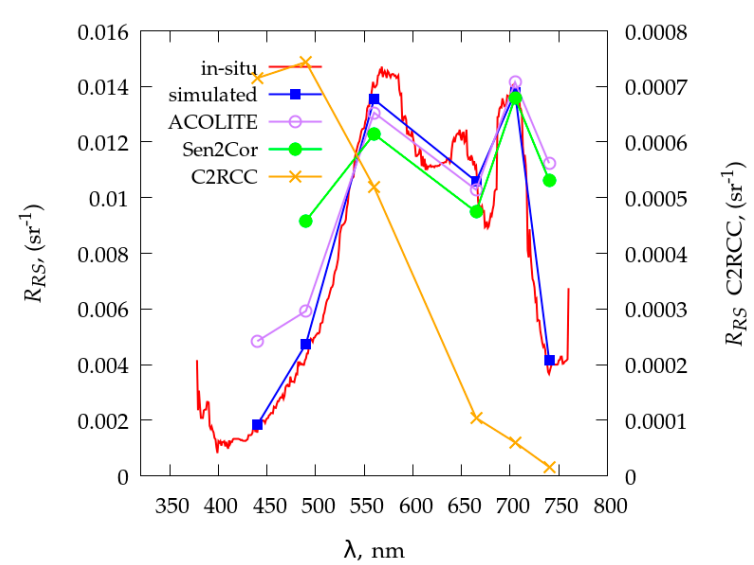

(b)

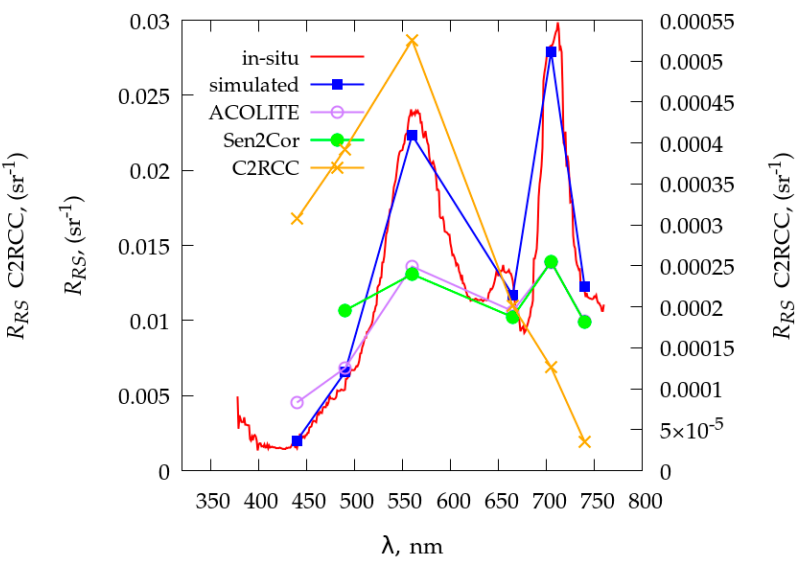

(d)

Figure 10. Comparison of Sentinel-2-retrieved $R_{r s}$ by means of atmospheric correction processors (ACOLITE, C2RCC, Sen2Cor) with in situ measurements in pixels depicted as stars in Figure 13a: (a) pixel \#1, (b) pixel \#2, (c) pixel \#3, and (d) pixel \#4. Red lines are hyperspectral measurement of $R_{r s}$, blue lines are measured $R_{r s}$ simulated on spectral bands of Sentinel-2/MSI according [14]. 
Based on the analysis results, we chose ACOLITE because it better reproduces the shape of the reflectance spectra. Additionally, ACOLITE is more flexible in configuration than SNAP plugins. It has the ability to apply coefficients for vicarious calibration, to choose AC algorithms (SWIR-SWIR or dark spectrum), to select bands for AC, etc. Table 6 shows the results of AC accuracy assessment by 671 match-up point.

Table 6. Atmospheric correction accuracy of ACOLITE at Sentinel-2/MSI bands based on 671 match-up points.

\begin{tabular}{|c|c|c|c|c|c|c|}
\hline$\lambda$ & 440 & 490 & 560 & 665 & 705 & 740 \\
\hline$R^{2}$ & 0.28 & 0.09 & 0.72 & 0.56 & 0.87 & 0.44 \\
\hline$R M S E, \mathrm{sr}^{-1}$ & 0.0014 & 0.0008 & 0.0041 & 0.0017 & 0.0054 & 0.0039 \\
\hline$M A P E, \%$ & 33.6 & 9.4 & 17.5 & 12.1 & 20.3 & 71.5 \\
\hline Bias, $\mathrm{sr}^{-1}$ & 0.0013 & -0.0001 & -0.0030 & -0.0015 & -0.0037 & 0.0032 \\
\hline Slope & 0.362 & 0.367 & 3.320 & 1.289 & 3.440 & 1.888 \\
\hline Intercept, $\mathrm{sr}^{-1}$ & 0.002 & 0.004 & -0.027 & -0.002 & -0.027 & -0.012 \\
\hline $\bar{R}_{r s, A C O L I T E} / \bar{R}_{r s, \text { insitu }}$ & 1.33 & 0.98 & 0.80 & 0.88 & 0.77 & 1.46 \\
\hline
\end{tabular}

The retrieved reflectance at B1 and B6 bands are greater than in situ measured ones. As one can see from Table 5 , the ratio $\bar{R}_{r s, A C O L I T E} / \bar{R}_{r s, i n s i t u}$ of the average $R_{r s}$ calculated by ACOLITE and in situ data at 671 match-up points for these two bands, was 0.0013 and $0.0032 \mathrm{sr}^{-1}$, while Bias was 0.0013 и $0.0032 \mathrm{sr}^{-1}$, respectively. Perhaps, this overestimation at B6 band was associated with the adjacency effect (Figure 10a,b). When this effect did not manifest, the retrieved values are close to the measured ones (Figure 10c,d). Reflectance at B2 band almost coincides $\left(\bar{R}_{r s, A C O L I T E} / \bar{R}_{r s, \text { insitu }}=0.98\right.$, Bias $=-0.0001 \mathrm{sr}^{-1}$ ) which was mainly connected with uniform distribution of retrieved $R_{r s}$ relatively to its true values, i.e., about half of the points were overestimated while the other half were underestimated (Figure 10). At B3-B5 bands we observed regular underestimation (Figure 10c,d) but for some pixels where $R_{r s}(560)=0.011-0.014$ we had the opposite situation (Figure 10a,b). Generally, the obtained estimation of $\bar{R}_{r S, A C O L I T E} / \bar{R}_{r s, i n s i t u}$ was close to presented in [15]. Since the estimates of AC accuracy made on the basis of independent measurements coincide, we can conclude that they are not associated with measurement errors, but with atmospheric correction. At the same time, there was a significant correlation with measurements $(r=0.85,0.75$, and 0.93$)$ so they can be used for the retrieval of Chl $a$ and TSM concentrations.

Correlation of the band ratio was better than for individual bands (Figure 11) because AC errors were partly compensated. For 2B and NDCI indices $R^{2}$ were 0.93 , while the slopes were 2.91 and 2.47. According to Figure 11a, the time series of $2 \mathrm{~B}$ ratio along the ship track had common features with ratio calculated by measurements, but their magnitudes differed on $50 \%$. Probably, this difference was caused not only by AC errors, but also a difference between in situ point measurements and area-averaged satellite data. According to Figure 8a, spatial heterogeneity of $\mathrm{Chl} a$ concentration on scales of tens of meters can vary by more than $50 \mathrm{mg} / \mathrm{m}^{3}$. In such circumstances, satellite data will have lower values. 


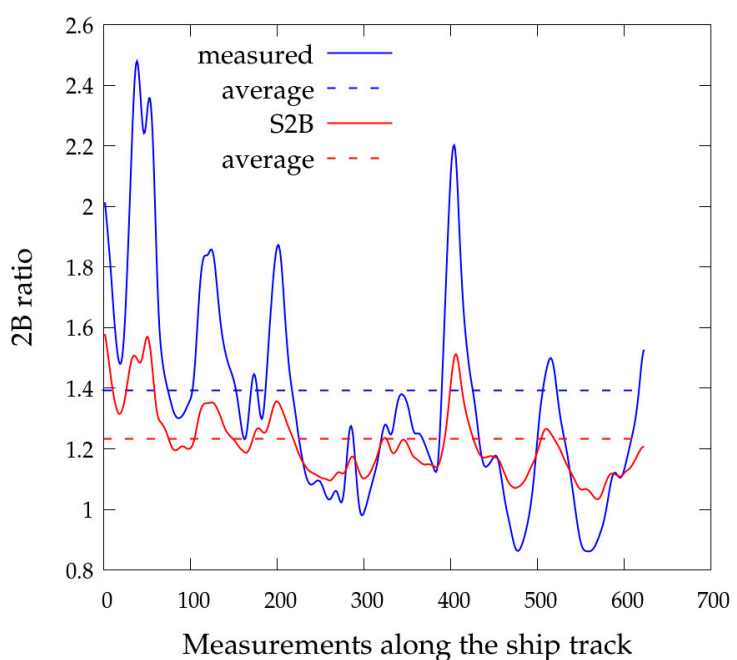

(a)

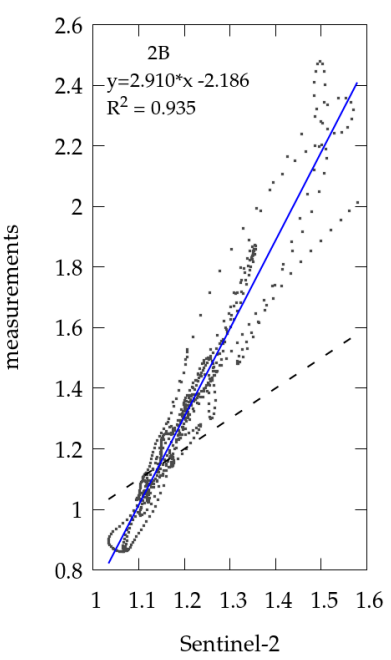

(b)

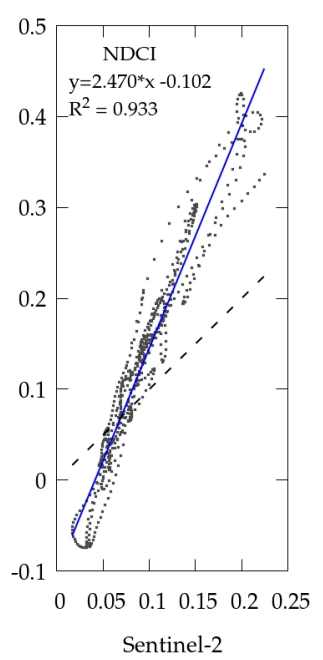

(c)

Figure 11. Comparison of retrieved band-ratio reflectance with in situ measurements $(\mathrm{N}=671)$ : (a) time series of the two-band ratio (2B) along ship track, (b) comparison of satellite-retrieved 2B index with measurements, and (c) comparison of the satellite-retrieved NDCI with measurements. Dashed lines on (b) and (c) represent the 1:1 line.

\subsection{Chl a and TSM Retrieval Models Using Sentinel-2 Data}

The high correlation of $R_{r s}$ at $\mathrm{B} 4$ and $\mathrm{B} 5$ bands with in situ measurements allows us to use them for satellite algorithm development. Linear and polynomial algorithms based on 2B and NDCI indices showed similar results (Table 7), but we chose the polynomial NDCI algorithm as the best (Figure 12).

Table 7. Remote sensing algorithms for $\mathrm{Chl} a$ retrieval and error analysis using RMSE, MAPE, and Bias on the basis of 671 match-up points. A total of 401 points were used for algorithm calibration, and the remaining 270 points for algorithm validation.

\begin{tabular}{|c|c|c|c|c|c|c|c|c|}
\hline \multirow[b]{2}{*}{ Index } & \multicolumn{4}{|c|}{ Calibration } & \multicolumn{4}{|c|}{ Validation } \\
\hline & $R^{2}$ & $a$ & $b$ & $c$ & $\begin{array}{c}\text { RMSE } \\
\left(\mathrm{mg} / \mathrm{m}^{3}\right)\end{array}$ & $\begin{array}{c}\text { MAPE } \\
(\%)\end{array}$ & $\begin{array}{c}\text { Bias } \\
\left(\mathrm{mg} / \mathrm{m}^{3}\right)\end{array}$ & Fits \\
\hline \multirow{2}{*}{$2 B$} & 0.84 & 64.536 & -57.800 & - & 3.27 & 13.89 & 0.003 & linear \\
\hline & 0.86 & -73.669 & 252.808 & -176.68 & 3.01 & 13.15 & 0.031 & poly \\
\hline \multirow{2}{*}{ NDCI } & 0.86 & 167.293 & 4.756 & - & 3.11 & 13.21 & -0.000 & linear \\
\hline & 0.86 & -300.260 & 235.556 & 1.586 & 3.02 & 13.14 & -0.001 & poly \\
\hline
\end{tabular}

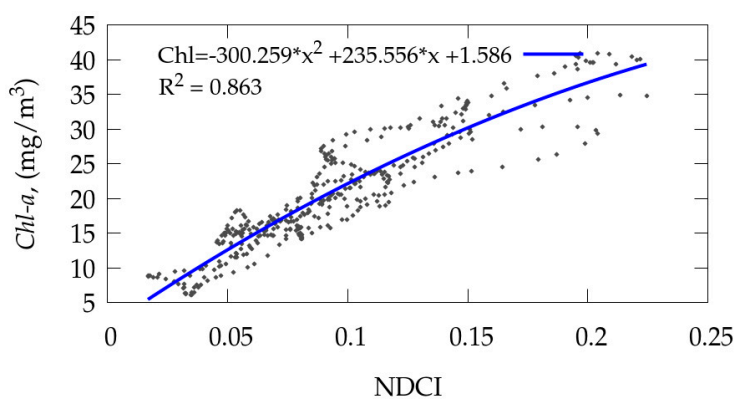

(a)

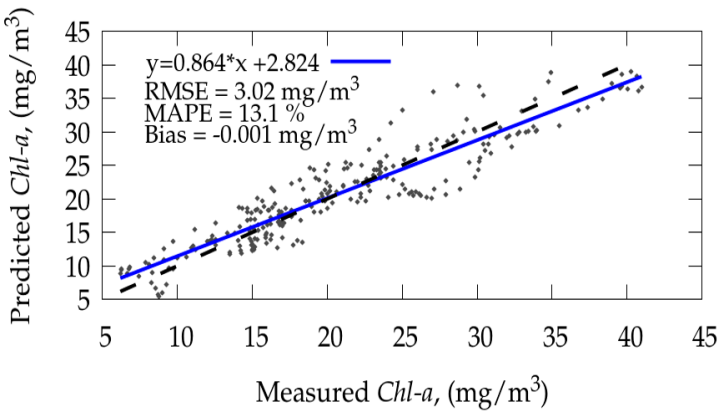

(b)

Figure 12. Results of $(\mathbf{a})$ calibration $(\mathrm{N}=401)$ and $(\mathbf{b})$ validation $(\mathrm{N}=270)$ of the remote sensing algorithm on the basis of the Normalized Difference Chlorophyll Index (NDCI) for Chl $a$ retrieval in the Gorky Reservoir. The dashed line represents the 1:1 line. 
2B index algorithm was used for TSM retrieval (Table 8). Since the dependence of 2B index on TSM concentration is close to linear, there was not noticeable difference with other regression models. Therefore we chose it as the best one (Figure 13).

Table 8. Remote sensing algorithms for TSM retrieval and error analysis using RMSE, MAPE, and Bias on base 671 match-up points. A total of 401 points were used for algorithm calibration, and the remaining 270 points for algorithm validation.

\begin{tabular}{|c|c|c|c|c|c|c|c|c|}
\hline \multirow[b]{2}{*}{ Index } & \multicolumn{4}{|c|}{ Calibration } & \multicolumn{4}{|c|}{ Validation } \\
\hline & $R^{2}$ & $a$ & $b$ & $c$ & $\begin{array}{l}\text { RMSE } \\
(\mathrm{mg} / \mathrm{L})\end{array}$ & $\begin{array}{c}\text { MAPE } \\
(\%)\end{array}$ & $\begin{array}{c}\text { Bias } \\
(\mathrm{mg} / \mathrm{L})\end{array}$ & Fits \\
\hline & 0.78 & 2.208 & 3.169 & & 0.13 & 1.56 & 0.0003 & linear \\
\hline $2 \mathrm{~B}$ & 0.78 & -0.406 & 3.246 & 2.513 & 0.13 & 1.56 & 0.0008 & poly \\
\hline
\end{tabular}

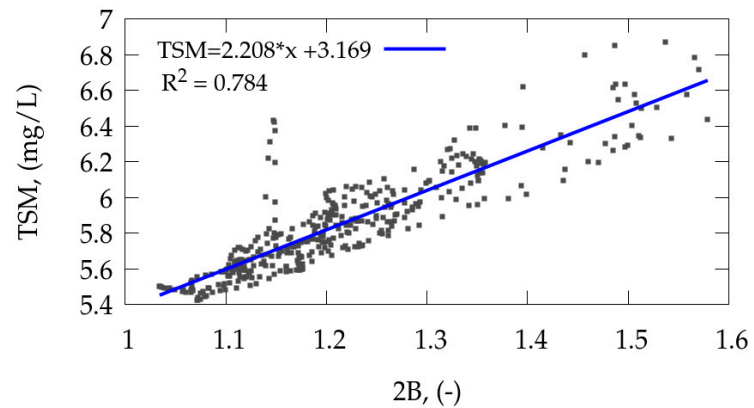

(a)

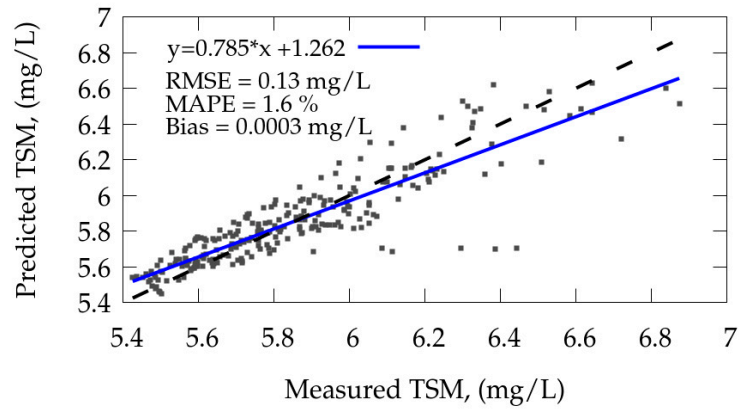

(b)

Figure 13. Results of (a) calibration $(\mathrm{N}=401)$ and $(\mathbf{b})$ validation (270) of the remote sensing two-band (2B) algorithm for TSM retrieval in the Gorky Reservoir. The dashed line represents the 1:1 line.

\subsection{Chl a and TSM Mapping Using Sentinel-2 Data}

The obtained algorithms were used to map Chl $a$ and TSM concentrations (Figure 14). The white line in Figure 14a shows the track that was close to satellite overpass. Corresponding to it, in situ data were chosen for the match-up dataset and for calibration and validation of satellite algorithms. The stars show pixels corresponding to four spectra in Figure 10. In the study area, the maximum observed Chl $a$ concentrations were about $40-50 \mathrm{mg} / \mathrm{m}^{3}$. At the same time, in the upstream area near left bank maximum Chl $a$ concentrations reached $70 \mathrm{mg} / \mathrm{m}^{3}$. Pixels with $\mathrm{Chl} a>70 \mathrm{mg} / \mathrm{m}^{3}$ were masked because $\rho_{w}(1600)$ exceeded the threshold value of 0.0215 , which was used to separate water from the clouds. Areas with high $\mathrm{Chl} a$ concentration corresponding to phytoplankton clusters are shown in Figure 1c.

In accordance with the results of the laboratory analyses and earlier study [75], the organic suspended matter was the main component ( 75\%) of suspended matter in the Gorky Reservoir in that period. Therefore, TSM and Chl $a$ maps greatly correlate with each other (Figure 14b). The maximum and average TSM concentrations were approximately $7-8 \mathrm{mg} / \mathrm{L}$ and $5.8 \mathrm{mg} / \mathrm{L}$, respectively, and agreed with in situ measurements (Table 2). A large number of suspended constituents, likely phytoplankton $\mathrm{Chl} a$, were concentrated along the left bank. 


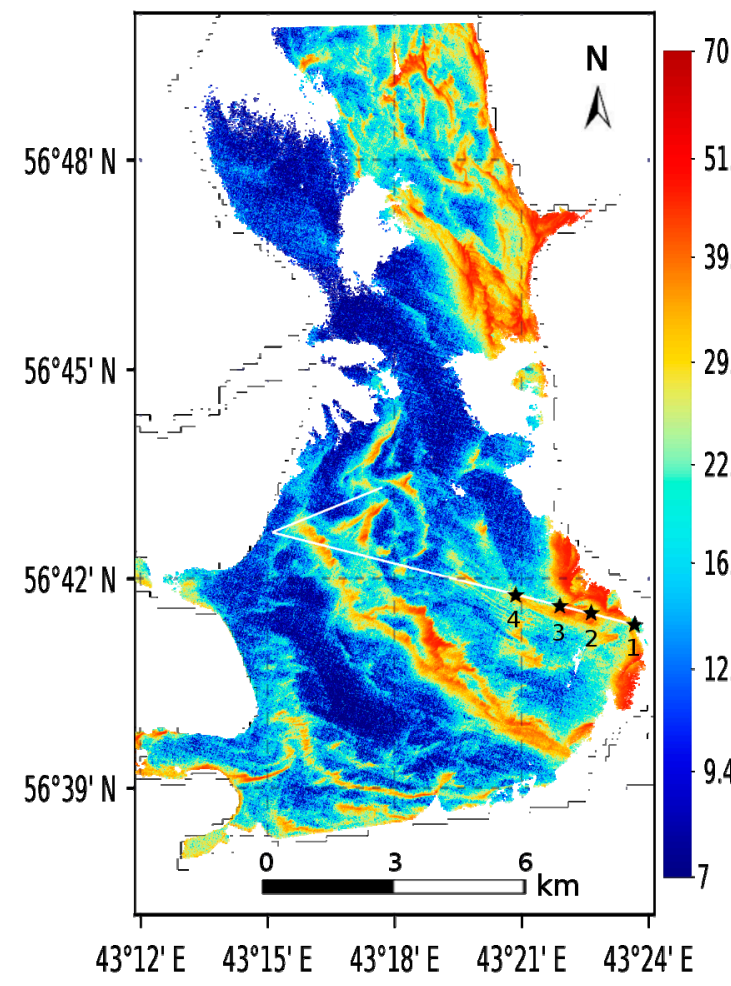

(a)



(b)

Figure 14. Spatial distribution of (a) $\mathrm{Chl} a, \mathrm{mg} / \mathrm{m}^{3}$, and (b) $\mathrm{TSM}, \mathrm{mg} / \mathrm{L}$, in the Gorky Reservoir on 21 September 2018. The white line shows to the section along which measurements were chosen for the match-up dataset, the stars show pixels correspond to four spectra in Figure 10.

\section{Discussion}

\subsection{Weakness of Station-Based Measurements}

Basic knowledge about the relation between remote sensing reflectance and water constituents in inland waters are obtained on traditional station-based in situ measurements in conditions close to calm weather. To correct $\mathrm{Chl} a$ retrieval in wind-wave conditions, corrective coefficients based on wind speed and wave fetch can be applied [76]. However, it is not a solution for water bodies when the optical properties of water change rapidly due to heterogeneous currents. On the example of the Azov Sea, significant variations in fluorescence of $\mathrm{Chl} a$ within every $300-\mathrm{m}$ and $1-\mathrm{km}$ lengths along the transect were found [24]. According to the comparison with the MERIS data, the authors made two important conclusions: 1) within-pixel spatial heterogeneity of $\mathrm{Chl} a$ distribution resulting in the station-based in situ measurements is not representative of the satellite pixel; and 2) an actual biophysical change in the water body between the times of in situ data collection and satellite acquisition should be taken into account. As a result, they offered to account within-pixel spatial heterogeneity and temporal variation through taking multiple measurements around each station so as to characterize the spatial variation within the satellite pixel area. In the Gorky Reservoir, water property varied in smaller scales, i.e., from tens to hundreds of meters. Additionally, daily variability of TSM and Chl $a$ was more than $150 \%$ and $400 \%$, respectively. Thus, for inland waters, like reservoirs with channel currents, this problem is more acute. Due to these examples, it becomes obvious that traditional station-based measurements are not effective for such water bodies. Therefore, the usage of remote sensing methods with known accuracy seems more reliable.

The approach proposed in the present study has not been described in the literature before. However, its components, like radiometric and LiDAR measurements, are widely used in limnological practice. It should be noted, those continuous radiometric measurements were repeatedly used 
for validation of atmospheric correction. In [77], for the AERONET OC program, a consequent measurement of the sky radiance and water leaving radiance from an oceanographic tower in the Adriatic Sea were realized using a modified photometer CE-318, Cimel. Again, in [78] synchronous measurements of such parameters were performed during transects. The authors indicated the real possibility of obtaining a large number of $R_{r s}$ spectra and their applicability for the validation of MODIS and VIIRS data. Such investigations have a basic goal: the changeover from manual long in situ measurements to automatic systems. To automate measurements, LiDAR systems are widely used in practical oceanology as express methods for assessing water quality [47-51]. They provided a high spatial resolution and a satisfied accuracy (according to some sources, like [52,79], the measurement error lies within 5-16\%).

Therefore, our approach for in situ measurement seems justified. Moreover, it can be considered as a small, but significant, step towards automated remote sensing of the optical properties of water and have particular importance for productive inland water.

\subsection{Chl a Retrieval Models}

To develop empirical models, we considered two band (2B) and three band (3B) NIR-red algorithms, as well as models based on NDCI and peak height at $705 \mathrm{~nm}$ (PH), which are well suited for Chl $a$ evaluation in eutrophic basins $[5,17,18,24,25,61-63]$. Chl $a$ concentrations varied from 1-100 mg/m³.

Relationships between $\mathrm{Chl} a$ concentration and $2 \mathrm{~B}$ and $\mathrm{PH}$ indices were close to linear. $R^{2}, R M S E$, Bias, and MAPE were similar for linear, polynomial, and power models (Table 3). On the contrary, the exponential model describing the nonlinear concentration growth from the index showed the worst result. 2B model for the Azov Sea $\left(\mathrm{Chl} a=0.6-60 \mathrm{mg} / \mathrm{m}^{3}\right)$ and Fremont Lake $\left(\mathrm{Chl} a=2-120 \mathrm{mg} / \mathrm{m}^{3}\right)$ were also linear in [24,61]. The linear relationship between $\mathrm{Chl} a$ concentration and $\mathrm{PH}$ was also obtained in [21] for the range 7-203 mg/m $\mathrm{m}^{3}$, and in [19] for the range 2-120 mg/m³. Additionally, the calibration coefficients of the linear PH model $\left(y=2231 x+12.7 ; R^{2}=0.80\right)$ [20] were quite close to those received in our research.

Nevertheless, despite the almost linear relationship between $\mathrm{Chl} a$ and 2B and $\mathrm{PH}$, there was a weak nonlinearity above $50 \mathrm{mg} / \mathrm{m}^{3}$ in our studies. Thus, the polynomial and power model $\mathrm{y}=(\mathrm{a} \times \text { Index }+\mathrm{b})^{\mathrm{c}}$ were slightly better (Table 3$)$.

The NDCI model is a nonlinear and is equally well described by both the 2nd order polynomial and the power model $y=(a \times \text { Index }+b)^{\mathrm{c}}$, which corresponds to [25]. Non-linear regression was also received for $3 \mathrm{~B}$ index (Table 3 , Figure $7 \mathrm{~b}$ ). These results mismatch [24,55], which showed that the 3B model with sufficient accuracy can be described by linear fit, and $[18,25]$ showed that nonlinearity appears after $100 \mathrm{mg} / \mathrm{m}^{3}$.

\subsection{TSM Retrieval Models}

Most of TSM algorithms were developed for sediment-rich waters, where water constituents significantly differ from those in highly productive waters of the Gorky Reservoir. We found that TSM concentration strongly correlates with $\mathrm{Chl} a$ concentration $(r \sim 0.85)$ during cyanobacteria bloom. Therefore, we investigated various models based on B3 (centered at $560 \mathrm{~nm}$ ) and B5 (centered at $705 \mathrm{~nm}$ ) bands associated with reflectance maxima in eutrophic waters and B6 band (centered at $740 \mathrm{~nm}$ ), which are minimally affected by the absorption of phytoplankton pigments.

It is known that TSM models in the red and NIR bands become strongly nonlinear at high concentrations, but could be linear in SWIR $[26,65]$. The analysis of regression models between TSM concentration and the simulated $R_{r S}$ at Sentinel-2/MSI bands [22] also showed that nonlinearity is more pronounced at shorter wavelengths. In sediment-rich waters (17-295 mg/L) on B1-B5 bands, the TSM concentration increases exponentially, but the dependencies at B6-B8 bands become a less steep and is described by power functions with the exponent 1.22-1.38.

We also found that the regressions become more linear with increasing wavelength (Table 5). Thus, the exponential and polynomial B3-based models $\left(R^{2}=0.71, \mathrm{RMSE}=0.66 \mathrm{mg} / \mathrm{L}, \mathrm{MAPE}=6.7 \%\right.$, 
Bias $=-0.004 \mathrm{mg} / \mathrm{L})$ are more accurate than the linear B3-based model $\left(R^{2}=0.69, \mathrm{RMSE}=0.68 \mathrm{mg} / \mathrm{L}\right.$, $\mathrm{MAPE}=7.2 \%$, Bias $=0.008 \mathrm{mg} / \mathrm{L})$. For B5 band, the difference between the exponential and linear models is not so obvious (Table 5). But the linear B6-based model $\left(R^{2}=0.74, \mathrm{RMSE}=0.63 \mathrm{mg} / \mathrm{L}\right.$, MAPE $=6.21 \%$, Bias $=0.006 \mathrm{mg} / \mathrm{L})$ has a minor advantage on the exponential one $\left(R^{2}=0.70\right.$, $\mathrm{RMSE}=0.70 \mathrm{mg} / \mathrm{L}, \mathrm{MAPE}=6.89 \%$, Bias $=0.016 \mathrm{mg} / \mathrm{L})$. However, for B6 band at concentrations above 9-10 mg/L, nonlinearity was also significantly manifested. In this regard, the polynomial B6 model are more accurate (Table 5, Figure 9a,b).

A few words should be said about the models based on B1, B2 and B4 bands, which are not shown in Table 5, because they showed the worse results. $R_{r s}$ at B1 band (centered at $440 \mathrm{~nm}$ ) did not correlate with TSM concentration (coefficient of correlation $r=0.17$ ) due to strong absorption of CDOM and phytoplankton pigments. $R_{r s}$ at B2 (centered at $490 \mathrm{~nm}$ ) and B4 (centered at $665 \mathrm{~nm}$ ) bands showed a moderate correlation ( $r$ is equal to 0.7 , and 0.66 , respectively). At the same time, $R_{r s}$ at B2 band had better correlation with TSM and provided more accurate predictions than $R_{r s}$ at B4 band. Perhaps, this can be explained by the non-optimal location of B4 band due to it partially coinciding with phycocyanin PC fluorescence and the second absorption maximum of phytoplankton pigments. We found that relationships between $\mathrm{Chl} a$ concentration and $R_{r s}$ at B4. The regressions of $\mathrm{Chl} a$ and TSM concentrations for the B4 band were worse than those for the B3 and B5 bands. Therefore, the usage of water reflectance in the red B4 band (centered at $665 \mathrm{~nm}$ ), which is often used to determine the TSM concentration in sediment-rich waters, is not suitable for highly productive inland waters. Among the single-band algorithms, B6-based models are more reliable, due to the absorption by CDOM and phytoplankton pigments at 740-760 $\mathrm{nm}$ is negligible and water-leaving radiance is mainly determined by the absorption of pure water and scattering on suspended particles.

Analysis of the MSI/Sentinel-2 bands sensitivity to changes in water constituents allowed to determine optimal bands for assessing their concentration, as well as confirmed previous conclusions about the large potential of Sentinel-2 data for monitoring highly productive internal waters [5,16-22]. Empirical models developed on the basis of 4087 in situ measurements reflect the regional characteristics of the optical characteristics in the Gorky Reservoir and can further be used for rapid estimation of Chl $a$ and TSM concentration by radiometric measurements.

\subsection{Atmospheric Correction}

Considered Sentinel-2 image processing tools were not allowed to retrieve remote sensing reflectance with the accuracy required for water applications. Only ACOLITE and Sen2Cor could reproduce the spectrum features at B3-B5 bands $\left(R^{2}=0.56-0.87\right)$, but significantly underestimated remote sensing reflectance: average and maximum values are less by $12-23 \%$ and 100-125\%, respectively (Table 6). The performance of blue bands (B1, B2) and the NIR band (B5) was considerably worse. It was noted in [68] that high performance of ACOLITE-retrieved reflectances in green (B3) and red (B4) channels mainly related to the higher reflectance range than in the blue and NIR bands. Large overestimation in NIR bands could be caused by the calibration performance at low radiances, adjacency effects, or surface effects. This explains the difference in the accuracy of the MSI bands that were also noted in $[5,15]$, but does not explain the large difference from the in situ measurements.

We understand that these differences may be due to both measurement inaccuracies and

atmospheric correction uncertainties. Therefore, we calculated the ratio $\bar{R}_{r s, A C O L I T E} / \bar{R}_{r s, \text { insitu }}$ in 671 match-up points (Table 6) and compared them with an independent study [15]. Since the results of this comparison were almost similar, we concluded that differences between satellite-retrieved and in situ measurements are associated with the AC uncertainties. Unfortunately, no other measurements have been made in the Gorky Reservoir. The two nearest AERONET stations are $600 \mathrm{~km}$ and $3600 \mathrm{~km}$ away, so we cannot use any other data to verify this assumption. In our opinion, this difference may also be caused by a discrepancy between the point in situ measurements and area-averaged satellite data in the case of high spatial heterogeneity of water optical properties. 
The atmospheric correction for turbid waters is a great challenge. It was shown in $[17,19]$ that L1C top-of-atmosphere radiances correlate better with water quality parameters than retrieved bottom-of-atmosphere radiances (L2A products). These, and our results of AC accuracy assessment, shows that there is a strong need for further improvement of the existing algorithms of Sentinel-2 image processing for aquatic applications.

Due to the poor accuracy of the retrieved $R_{r s}$ data, we cannot use them in empirical models. However, we used the B4 and B5 bands, which are well correlated with in situ measurements, to develop a remote sensing algorithm on the basis of a dataset of 671 matchups. The developed NDCI algorithm for retrieval of $\mathrm{Chl} a$ concentration (Figure 12) and the 2B algorithm for retrieval of TSM concentration (Figure 13) have good accuracy $\left(R^{2}=0.86, R M S E=3.02 \mathrm{mg} / \mathrm{m}^{3} ; M A P E=13.14 \% ;\right.$ Bias $=-0.001 \mathrm{mg} / \mathrm{m}^{3}$; slope $=0.864)$ and $\left(R^{2}=0.78, \mathrm{RMSE}=0.13 \mathrm{mg} / \mathrm{L}, \mathrm{MAPE}=1.56 \%\right.$, Bias $=0.0003 \mathrm{mg} / \mathrm{L}$, slope $\left.=0.785\right)$ accordingly. These algorithms can be further used for mapping of $\mathrm{Chl} a$ and TSM concentration in the Gorky Reservoir and neighboring inland waters.

\subsection{Future Plans}

After completing this study, the following ways to improve measurement accuracy can be taken: (i) LiDAR calibration by a larger number of water samples [37]; (ii) the usage of a spectrometer with a collecting lens that provides measurements from a footprint similar to that of the LiDAR; and (iii) orientation of both devices at the same point of the water surface. At the same time, we realize that the usage of three synchronized spectrometers for radiometric measurements $[57,58]$ will provide greater accuracy, guarantee clear result comparability, and eliminate the measurements of the sky radiance and the radiance of the Lambertian surface between transects. Additionally, future efforts should be focused on approaches of validation and analysis of its uncertainties. For this, the intercomparison with traditional radiometric protocols will be planned. To assess the propriety of aerosol model selection for atmospheric correction, we are going to measure the aerosol optical thickness (AOT) using a MICROTOPS portable sun photometer.

\section{Conclusions}

We proposed the approach of remote rapid in situ measurements with the resolution of $8 \mathrm{~m}$ suitable for inland waters with spatial heterogeneity and temporal variation of its optical properties. It is based on the simultaneous measurements of the remote sensing reflectance by the single spectrometer Ocean Optics USB 2000 and the concentration of water constituents by the ultraviolet fluorescent LiDAR UFL-9, both installed on a high-speed gliding motorboat. This approach was tested on the Gorky Reservoir of the Russian Federation under Sentinel-2B acquisition on 21 September 2018. As a result, the dataset including 4087 values of $\mathrm{Chl} a, \mathrm{TSM}$, and $R_{r s}$ were collected from the area of $150 \mathrm{~km}^{2}$ per two hours.

The regional Chl $a$ and TSM models were developed based on 2B, 3B, NDCI and PH indices. To assess their accuracy we investigated linear, polynomial, exponential, and two power functions for approximations. All Chl $a$ models, except the exponential one, showed approximately the same efficiency. Power models showed slightly better results due to a more accurate description of high Chl $a$ concentrations ( $\mathrm{Chl} a>80 \mathrm{mg} / \mathrm{m}^{3}$ ). According to TSM retrieval, the single-band TSM models were more effective than the models using band ratios. The peak height at $705 \mathrm{~nm}$ (PH models) was also a representative parameter for Chl $a$ and TSM prediction.

Atmospheric correction of the satellite image was realized using SeaDAS, ACOLITE, C2RCC, iCOR, and Sen2Cor processing software. All of them did not allow retrieval of Rrs spectra with sufficient accuracy. At the qualitative level ACOLITE and Sen2Cor reproduce the spectrum features at B3-B5 bands $\left(R^{2}=0.56-0.87\right)$, but significantly underestimate remote sensing reflectance: average and maximum values are less by $12-23 \%$ and $100-125 \%$, respectively. The retrieved remote sensing reflectance at B1, B2, and B6 bands are weakly correlated with measurements $\left(R^{2}<0.44\right)$. The high correlation of remote sensing reflectance at B4 and B5 bands with in situ measurements allowed us to 
develop the algorithms to predict $\mathrm{Chl} a$ and TSM concentration using ACOLITE processing software and applied them for mapping in the Gorky Reservoir.

Both empirical models and remote-sensing algorithms can be applied for Chl $a$ and TSM retrieval in next ranges: $1<\mathrm{Chl} a<100 \mathrm{mg} / \mathrm{m}^{3}$ and $5<\mathrm{TSM}<20 \mathrm{mg} / \mathrm{L}$. These models can be adapted for neighboring reservoirs, for example, for the other seven reservoirs on the Volga River. At the same time, the proposed approach of in situ measurements can be useful in limnological monitoring of highly productive water bodies with sharp spatiotemporal variability of their optical properties.

Author Contributions: A.A.M. realized the conceptualization, methodology, in situ measurements, data analyses, as well as wrote the original manuscript. S.V.F. performed data processing, analyses, and validation, and wrote the original manuscript. They contributed towards editing and reviewing the manuscript. V.V.P. performed LiDAR measurements and data processing. E.N.K. supported the radiometric in situ measurements and data processing.

Funding: This research was funded by the Russian Science Foundation (Project RSF 17-77-10120) regarding the development of regional bio-optical algorithms and by the Ministry of Science and Education of Russian Federation (theme no. 0149-2019-0003 and Agreement 14.W03.31-0006) regarding the field ground-truth LiDAR data collection.

Acknowledgments: We are grateful to Dmitriy Kostitsyn for using his unique speed motorboat in our subsatellite measurements, Boris Konovalov for laboratory analysis, and George Leshov for his help in equipment setup. The authors also thank the anonymous reviewers for their useful comments and suggestions.

Conflicts of Interest: The authors declare no conflict of interest.

\section{References}

1. Chorus, I.; Falconer, I.R.; Salas, H.J.; Bartram, J. Health risks caused by freshwater cyanobacteria in recreational waters. J. Toxicol. Environ. Health B Crit. Rev. 2000, 3, 323-347. [PubMed]

2. Fitzgerald, D.J.; Cunliffe, D.A.; Burch, M.D. Development of health alerts for cyanobacteria and related toxins in drinking water in south Australia. Environ. Toxicol. 1999, 14, 203-209. [CrossRef]

3. Aibulatov, N.A.; Zavialov, P.O.; Pelevin, V.V. Some features of self-purification of Russian Black Sea shoaling waters near river entries. Geo. Ecol. 2008, 4, 301-310.

4. Matsushita, B.; Yang, W.; Yu, G.; Oyama, Y.; Yoshimura, K.; Fukushima, T. A hybrid algorithm for estimating the Chlorophyll-a concentration across different trophic states in Asian inland waters. ISPRS J. Photogramm. Sens. 2015, 102, 28-37. [CrossRef]

5. Ansper, A.; Alikas, K. Retrieval of Chlorophyll $a$ from Sentinel-2 MSI Data for the European Union Water Framework Directive Reporting Purposes. Remote Sens. 2019, 11, 64. [CrossRef]

6. Mishra, D.R.; Ogashawara, I.; Gitelson, A.A. Bio-Optical Modeling and Remote Sensing of Inland Waters; Elsevier: Amsterdam, The Netherlands, 2017; pp. 7-8.

7. Tikhomirov, O.A.; Bocharov, A.V.; Komissarov, A.B.; Khizhnyak, S.D.; Pakhomov, P.M. Use of sensor LANDSAT 8 (OLI) for evaluation of indicators turbidity, color and Chlorophyll content in water reservoir ivankovskoye. Vestn. Tver. Gos. Univ. Seriya Him. 2016, 2, 230-244.

8. Cherneckij, M.Y.; Shevyrnogov, A.P.; Vysockaya, G.S.; Sid'ko, A.F. Opredelenie pervichnoj produkcii na Krasnoyarskom vodohranilishche po sputnikovym dannym MODIS. Sovremennye Problemy Distantsionnogo Zondirovaniya Zemli Iz Kosmosa 2004, 1, 508-513.

9. Korchemkina, E.N.; Molkov, A.A. Regional bio-optical algorithm for Gorky Reservoir: First results. Sovremennye Problemy Distantsionnogo Zondirovaniya Zemli iz Kosmosa 2018, 3, 184-192. [CrossRef]

10. Sodnomov, B.V.; Tsydypov, B.Z.; Garmayev, E.Z. Determination of the Chlorophyll "A" concentration in lake Baikal using remote sensing methods. In Proceedings of the International Conference and Early Career Scientists School on Envirionmental Observations, Modeling and Information System, Tomsk, Russia, 11-16 July 2016.

11. Heim, B.; Fietz, S.; Oberhaensli, H.; Kaufmann, H. Investigation of terrigenous input and phytoplankton in Lake Baikal (RU) using SeaWiFS Ocean Colour data. In Proceedings of the 31th Int. Symp. Remote Sensing of Environment, St. Petersburg, Russia, 18-19 June 2005.

12. Pozdnyakov, D.V.; Korosov, A.A.; Petrova, N.A.; Grassle, H. Multi-year satellite observations of Lake Ladoga's biogeochemical dynamics in relation to the lake's trophic status. J. Great Lakes 2013, 39, $34-45$. [CrossRef] 
13. Drusch, M.; Del Bello, U.; Carlier, S.; Colin, O.; Fernandez, V.; Gascon, F.; Hoersch, B.; Isola, C.; Laberinti, P.; Martimort, P. Sentinel-2: ESA's Optical High-Resolution Mission for GMES Operational Services. Remote Sens. Environ. 2012, 120, 25-36. [CrossRef]

14. Pahlevan, N.; Sarkar, S.; Franz, B.A.; Balasubramanian, S.V.; He, J. Sentinel-2 multispectral instrument (MSI) data processing for aquatic science applications: demonstrations and validations. Remote Sens. Environ. 2017, 201, 47-56. [CrossRef]

15. Martins, V.S.; Barbosa, C.C.F.; de Carvalho, L.A.S.; Jorge, D.S.F.; Lobo, F.d.L.; Novo, E.M.L. Assessment of atmospheric correction methods for sentinel-2 MSI images applied to amazon floodplain lakes. Remote Sens. 2017, 9, 322. [CrossRef]

16. Dörnhöfer, K.; Göritz, A.; Gege, P.; Pflug, B.; Oppelt, N. Water constituents and water depth retrieval from Sentinel-2a-a first evaluation in an oligotrophic lake. Remote Sens. 2016, 8, 941. [CrossRef]

17. Grendaitè, D.; Stonevičius, E.; Karosienè, J.; Savadova, K.; Kasperovičienè, J. Chlorophyll-a concentration retrieval in eutrophic lakes in Lithuania from Sentinel-2 data. Geol. Geogr. 2018, 4, 15-28. [CrossRef]

18. Watanabe, F.; Alcântara, E.; Rodrigues, T.; Rotta, L.; Bernardo, N.; Imai, N. Remote sensing of the Chlorophyll-a based on OLI/Landsat-8 and MSI/Sentinel-2A (Barra Bonita reservoir, Brazil). An. Acad. Bras. Cienc. 2018, 90, 1987-2000. [CrossRef] [PubMed]

19. Toming, K.; Kutser, T.; Laas, A.; Sepp, M.; Paavel, B.; Nõges, T. First experiences in mapping lake water quality parameters with Sentinel-2 MSI imagery. Remote Sens. 2016, 8, 640. [CrossRef]

20. Ruescas, A.B.; Hieronymi, M.; Mateo-Garcia, G.; Koponen, S.; Kallio, K.; Camps-Valls, G. Machine Learning Regression Approaches for Colored Dissolved Organic Constituents (CDOM) Retrieval with S2-MSI and S3-OLCI Simulated Data. Remote Sens. 2018, 10, 786. [CrossRef]

21. Kutser, T.; Paavel, B.; Verpoorter, C.; Ligi, M.; Soomets, T.; Toming, K.; Casal, G. Remote sensing of black lakes and using $810 \mathrm{~nm}$ reflectance peak for retrieving water quality parameters of optically complex waters. Remote Sens. 2016, 8, 497. [CrossRef]

22. Liu, H.; Li, Q.; Shi, T.; Hu, S.; Wu, G.; Zhou, Q. Application of sentinel 2 MSI images to retrieve suspended particulate constituents concentrations in Poyang Lake. Remote Sens. 2017, 9, 761. [CrossRef]

23. Pahlevan, N.; Chittimalli, S.K.; Balasubramanian, S.V.; Vellucci, V. Sentinel-2/Landsat-8 product consistency and implementation for monitoring aquatic systems. Remote Sens. Environ. 2019, 220, 19-29. [CrossRef]

24. Moses, W.J.; Gitelson, A.A.; Berdnikov, S.; Povazhnyy, V. Satellite estimation of Chlorophyll-a concentration using the red and NIR bands of MERIS-2014; The Azov sea case study. IEEE Geosci. Remote Sens. Lett. 2009, 6, 845-849. [CrossRef]

25. Mishra, S.; Mishra, D.R. Normalized difference Chlorophyll index: a novel model for remote estimation of Chlorophyll-a concentration in turbid productive waters. Remote Sens. Environ. 2012, 117, 394-406. [CrossRef]

26. Nechad, B.; Ruddick, K.; Park, Y. Calibration and validation of a generic multisensor algorithm for mapping of total suspended constituents in turbid waters. Remote Sens. Environ. 2010, 114, 854-866. [CrossRef]

27. Bolgov, M.V.; Demin, A.P. Water-Management and Environmental Problems of the Lower Volga and Ways to Their Solution. Water Resour. 2018, 45, 297-305. [CrossRef]

28. Moiseenko, T.I.; Gashkina, N.A.; Sharova, Y.N. Volga River: Pollution, water quality, toxic contamination and fish health. In River Ecosystems: Dynamics, Management and Conservation; Elliot, H.S., Martin, L.E., Eds.; Nova Science Publishers: Hauppauge, NY, USA, 2011; pp. 150-180.

29. The Time (Newspaper). Volga River being Poisoned by Pollution. Available online: https://www.thetimes.co. uk/article/volga-river-being-poisoned-by-pollution-8606ljzlv (accessed on 5 March 2019).

30. Butorin, N.V. Hydrological Processes and Water Mass Dynamics in Volga System Reservoirs; Nauka: Leningrad, USSR, 1969.

31. Korneva, L.G.; Solov'eva, V.V. Ecological-Physiological Studies of Algae and Their Significance for Natural Water Assessment; YaGTU: Yaroslavl, Russia, 1996.

32. Mineeva, N.M. Concentrations of Photosynthetic Pigments in Upper Volga Reservoirs. Biol. Inn. Water. 2006, 1,31-40.

33. Mineeva, N.M.; Bikbulatova, E.M. The contribution of primary production to the overall organic matter pool in Volga reservoirs. Water Resour. 2008, 35, 562. [CrossRef] 
34. Molkov, A.A.; Kapustin, I.A.; Shchegolkov, Y.B.; Vodeneeva, E.L.; Kalashnikov, I.N. On correlation between inherent optical properties at $650 \mathrm{~nm}$, Secchi depth and blue-green algal abundance for the Gorky Reservoir. Fundam. Apll. Hydrophys. 2018, 11, 26-33.

35. Kapustin, I.A.; Molkov, A.A. Investigation of the currents and depths structure in the lake part of the Gorky Reservoir using acoustical measuring instruments. Russian Meteorol. Hydrol. 2019, in press.

36. Rp5. Regional Prognosis. Available online: https://rp5.ru (accessed on 5 March 2019).

37. Palmer, S.C.; Pelevin, V.V.; Goncharenko, I.V.; Kovács, A.; Zlinszky, A.; Présing, M.; Horváth, H.; Nicolás-Perea, V.; Balzter, H.; Tóth, V. Ultraviolet Fluorescence Lidar (UFL) as a Measurement Tool for Water Quality Parameters in Turbid Lake Conditions. Remote Sens. 2013, 5, 4405-4422. [CrossRef]

38. Mueller, J.L.; Pietras, C.; Hooker, S.B.; Austin, R.W.; Miller, M.; Knobelspiesse, K.D.; Frouin, R.; Holben, B.; Voss, K. Ocean Optics Protocols For Satellite Ocean Color Sensor Validation, Revision 4, Volume II: Instrument Specifications, Characterization and Calibration. NASA's Goddard Space Flight Center: Greenbelt, MD, USA, 2003; pp. 1-56.

39. SCOR-UNESCO. Report of SCOR-UNESCO working group 17 on determination of photosynthetic pigments in Sea Water. In Monograph of Oceanography Methodology; UNESCO: Paris, France, 1966; Volume 1, pp. 9-18.

40. Jeffrey, S.W.; Humphrey, G.F. New spectrophotometric equations for determining chlorophylls a, b, c1 and c2 in higher plants, algae and natural phytoplankton. Biochem. Physiol. Pflanz. 1975, 167, 191-194. [CrossRef]

41. Mueller, J.L.; Bidigare, R.R.; Trees, C.; Balch, W.M.; Dore, J.; Drapeau, D.T.; Karl, D.; Van Heukelem, L.; Perl, J. Ocean Optics Protocols For Satellite Ocean Color Sensor Validation, Revision 5, Volume 5: Biogeochemical and Bio-Optical Measurements and Data Analysis Protocols; NASA's Goddard Space Flight Center: Greenbelt, MD, USA, 2003; pp. 5-24.

42. Bao, Y.; Tian, Q.; Chen, M.A. Weighted Algorithm Based on Normalized Mutual Information for Estimating the Chlorophyll-a Concentration in Inland Waters Using Geostationary Ocean Color Imager (GOCI) Data. Remote Sens. 2015, 7, 11731-11752. [CrossRef]

43. Alikas, K.; Kangro, K.; Reinart, A. Detecting cyanobacterial blooms in large North European lakes using the Maximum Chlorophyll Index. Oceanolong 2010, 52, 237-257. [CrossRef]

44. Peng, F.; Liu, S.; Xu, H.; Li, Z. A Comparative Study on the Analysis Methods for Chlorophyll-a. Adv. Mater. Res. 2013, 726-731, 1411-1415. [CrossRef]

45. Santos, A.C.A.; Calijuri, M.C.; Moraes, E.M.; Adorno, M.A.T.; Falco, P.B.; Carvalho, D.P.; Deberdt, G.L.B.; Benassi, S.F. Comparison of three methods for Chlorophyll determination: Spectrophotometry and Fluorimetry in samples containing pigment mixtures and spectrophotometry in samples with separate pigments through High Performance Liquid Chromatography. Acta Limnol. Bras. 2003, 15, 7-18.

46. Konovalov, B.V.; Kravchishina, M.D.; Belyaev, N.A.; Novigatsky, A.N. Determination of the concentration of mineral particles and suspended organic substance based on their spectral absorption. Oceanolong 2014, 54, 660-667. [CrossRef]

47. Fiorani, L.; Okladnikov, I.G.; Palucci, A. Remote Sensing of the Southern Ocean by MERIS, MODIS, Seawifs and ENEA Lidar. J. Optoelectro. Adv. Mater. 2008, 10, 1482-1488.

48. Hoge, F.E.; Lyon, P.E.; Swift, R.N.; Yungel, J.K.; Abbott, M.R.; Letelier, R.M.; Esaias, W.E. Validation of Terra-MODIS Phytoplankton Chlorophyll Fluorescence Line Height. I. Initial Airborne Lidar Results. Appl. Opt. 2003, 42, 2767-2771. [CrossRef]

49. Ma, S.; Liu, Z.S.; Zhang, K.L.; Li, Z.G.; He, S.Y. Field Experiment of an Airborne Oceanographic Lidar and Comparison with a Moderate Resolution Imaging Spectroradiometer. Lasers Eng. 2006, 16, 413-421.

50. Moreno-Madrinan, M.J.; Al-Hamdan, M.Z.; Rickman, D.L.; Muller-Karger, F.E. Using the Surface Reflectance MODIS Terra Product to Estimate Turbidity in Tampa Bay, Florida. Remote Sens. 2010, 2, 2713-2728. [CrossRef]

51. Palmer, S.C.J.; Kutser, T.; Hunter, P.D. Remote Sensing of Inland Waters: Challenges, Progress and Future Directions. Remote Sens. Environ. 2015, 157, 1-8. [CrossRef]

52. Pelevin, V.; Zlinszky, A.; Khimchenko, E.; Toth, V. Ground truth data on Chlorophyll-a, chromophoric dissolved organic constituents and suspended sediment concentrations in the upper water layer as obtained by LIF Lidar at high spatial resolution. Int. J. Remote Sens. 2017, 38, 1967-1982. [CrossRef] 
53. Pelevin, V.; Zavialov, P.; Konovalov, B.; Zlinszky, A.; Palmer, S.; Toth, V.; Goncharenko, I.; Khymchenko, L.; Osokina, V. Measurements with high spatial resolution of Chlorophyll-a, CDOM and total suspended constituents in coastal zones and inland water basins by the portable UFL Lidar. In Proceedings of the 35th EARSeL Symposium-European Remote Sensing: Progress, Challenges and Opportunities, Stockholm, Sweden, 15-19 June 2015.

54. Mobley, C.D. Estimation of the remote sensing reflectance from above-Water methods. Appl. Optics 1999, 38, 7442-7455.

55. Gitelson, A.A.; Gurlin, D.; Moses, W.J.; Barrow, T. A bio-optical algorithm for the remote estimation of the Chlorophyll-a concentration in case 2 waters. Environ. Res. Lett. 2009, 4, 1-5. [CrossRef]

56. Lee, M.E.; Shybanov, E.B.; Korchemkina, E.N.; Martynov, O.V. Retrieval of concentrations of seawater natural components from reflectance spectrum. In Proceedings of the 22nd International Symposium on Atmospheric and Ocean Optics: Atmospheric Physics, Tomsk, Russian, 30 June-3 July 2016.

57. Ruddick, K.G.; De Cauwer, V.; Park, Y.J.; Moore, G. Seaborne measurements of near infrared water-leaving reflectance: The similarity spectrum for turbid waters. Limnol. Oceanogr. 2006, 51, 1167-1179. [CrossRef]

58. Zibordi, G.; Ruddick, K.; Ansko, I.; Moore, G.; Kratzer, S.; Icely, J.; Reinart, A. In situ determination of the remote sensing reflectance: An inter-comparison. Ocean Sci. 2012, 8, 567-586. [CrossRef]

59. Karalli, P.G.; Kopelevich, O.V.; Sahling, I.V.; Sheberstov, S.V.; Pautova, L.V.; Silkin, V.A. Validation of remote sensing estimates of coccolitophore bloom parameters in the Barents Sea from field measurements. Fundam. Apll. Hydrophys. 2018, 11, 63-66.

60. O'Reilly, J.E.; Maritorena, S. SeaWiFS Postlaunch Calibration and Validation Analyses, Part 3; NASA's Goddard Space Flight Center: Greenbelt, MD, USA, 2000; 49p.

61. Gilerson, A.A.; Gitelson, A.A.; Zhou, J.; Gurlin, D.; Moses, W.; Ioannou, I.; Ahmed, S.A. Algorithms for remote estimation of Chlorophyll-a in coastal and inland waters using red and near infrared bands. Opt. Express 2010, 18, 24109-24125. [CrossRef]

62. Gurlin, D.; Gitelson, A.A.; Moses, W.J. Remote estimation of Chl-a concentration in turbid productive waters-Return to a simple twoband NIR-red model. Remote Sens. Environ. 2011, 115, 3479-3490. [CrossRef]

63. Bernardo, N.; Watanabe, F.; Rodrigues, T.; Alcântara, E. Evaluation of the suitability of MODIS, OLCI and OLI for mapping the distribution of total suspended constituents in the Barra Bonita Reservoir (Tietê River, Brazil). Remote Sens. Appl. Soc. Environ. 2016, 4, 68-82.

64. Dekker, A.G.; Vos, R.J.; Peters, S.W.M. Analytical algorithms for lake water TSM estimation for retrospective analyses of TM and SPOT sensor data. Int. J. Remote Sens. 2002, 23, 15-35. [CrossRef]

65. Knaeps, E.; Ruddick, K.G.; Doxaran, D.; Dogliotti, A.I.; Nechad, B.; Raymaekers, D.; Sterckx, S. A SWIR based algorithm to retrieve total suspended constituents in extremely turbid waters. Remote Sens. Environ. 2015, 168, 66-79. [CrossRef]

66. Copernicus Open Access Hub. Available online: https://scihub.copernicus.eu/ (accessed on 5 March 2019).

67. Baith, K.; Lindsay, R.; Fu, G.; McClain, C.R. SeaDAS: Data analysis system developed for ocean color satellite sensors. EOS Trans. Am. Geophys. Union 2001, 82, 202. [CrossRef]

68. Vanhellemont, $Q$. Adaptation of the dark spectrum fitting atmospheric correction for aquatic applications of the Landsat and Sentinel-2 archives. Remote. Sens. Environ. 2019, 225, 175-192. [CrossRef]

69. Dogliotti, A.I.; Gossn, J.I.; Vanhellemont, Q.; Ruddick, K.G. Detecting and Quantifying a Massive Invasion of Floating Aquatic Plants in the Río de la Plata Turbid Waters Using High Spatial Resolution Ocean Color Imagery. Remote Sens. 2018, 10, 1140. [CrossRef]

70. Luo, Y.; Doxaran, D.; Ruddick, K.; Shen, F.; Gentili, B.; Yan, L.; Huang, H. Saturation of water reflectance in extremely turbid media based on field measurements, satellite data and bio-optical modelling. Opt. Express 2018, 26, 10435-10451. [CrossRef]

71. Novoa, S.; Doxaran, D.; Ody, A.; Vanhellemont, Q.; Lafon, V.; Lubac, B.; Gernez, P. Atmospheric Corrections and Multi-Conditional Algorithm for Multi-Sensor Remote Sensing of Suspended Particulate Constituents in Low-to-High Turbidity Levels Coastal Waters. Remote Sens. 2017, 9, 61. [CrossRef]

72. Brockmann, C.; Doerffer, R.; Marco, P.; Stelzer, K.; Embacher, S.; Ruescas, A. Evolution Of The C2RCC Neural Network For Sentinel 2 and 3 For The Retrieval of Ocean ocean colour products in normal and extreme optically complex waters. In Proceedings of the conference held Living Planet Symposium, Prague, Czech Republic, 9-13 May 2016. 
73. De Keukelaere, L.; Sterckx, S.; Adriaensen, S.; Knaeps, E.; Reusen, I.; Giardino, C.; Bresciani, M.; Hunter, P.; Neil, C.; Van der Zande, D.; et al. Atmospheric correction of Landsat-8/OLI and Sentinel-2/MSI data using iCOR algorithm: Validation for coastal and inland waters. Eur. J. Remote Sens. 2018, 51, 525-542. [CrossRef]

74. Sen2Cor. Configuration and User Manual. 2019. Ref. S2-PDGS-MPC-L2A-SUM-V2.8. Is.2. Available online: http://step.esa.int/thirdparties/sen2cor/2.8.0/docs/S2-PDGS-MPC-L2A-SUM-V2.8.pdf (accessed on 21 May 2019).

75. Mineeva, N.M. Plankton Primary Production in the Volga River Reservoirs; Print House: Yaroslavl, Russia, 2009.

76. Xue, K.; Zhang, Y.; Duan, H.; Ma, R.; Loiselle, S.; Zhang, M. A Remote Sensing Approach to Estimate Vertical Profile Classes of Phytoplankton in a Eutrophic Lake. Remote. Sens. 2015, 7, 14403-14427. [CrossRef]

77. Zibordi, G.; Melin, F.; Hooker, S.B.; D'Alimonte, D.; Holben, B. An Autonomous Above-Water System for the Validation of Ocean Color Radiance Data. IEEE Trans. Geosci. Sens. 2004, 42, 401-415. [CrossRef]

78. Brando, V.E.; Lovell, J.L.; King, E.A.; Boadle, D.; Scott, R.; Schroeder, T. The Potential of Autonomous Ship-Borne Hyperspectral Radiometers for the Validation of Ocean Color Radiometry Data. Remote Sens. 2016, 8, 150. [CrossRef]

79. Chen, P.; Pan, D.; Mao, Z.; Liu, H. A Feasible Calibration Method for Type 1 Open Ocean Water LiDAR Data Based on Bio-Optical Models. Remote Sens. 2019, 11, 172. [CrossRef]

(C) 2019 by the authors. Licensee MDPI, Basel, Switzerland. This article is an open access article distributed under the terms and conditions of the Creative Commons Attribution (CC BY) license (http://creativecommons.org/licenses/by/4.0/). 